Submitted to Materials Science and Engineering A, June, 2014

Revised July, 2014

\title{
Cyclic deformation and fatigue of extruded ZK60 magnesium alloy with aging effects
}

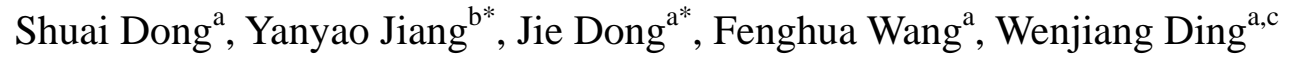 \\ ${ }^{a}$ National Engineering Research Center of Light Alloy Net Forming, Shanghai Jiao Tong \\ University, Shanghai 200240, China \\ Phone: 21-3420-3052, Fax: 21-3420-2794, E-mail: jiedong@ sjtu.edu.cn \\ ${ }^{\mathrm{b}}$ University of Nevada, Department of Mechanical Engineering (312), Reno, NV 89557, USA, \\ Phone: 775-784-4510, Fax: 775-784-1701, E-mail: yjiang@unr.edu \\ ${ }^{c}$ Key State Laboratory of Metal Matrix Composite, Shanghai Jiao Tong University, Shanghai \\ 200240, China
}

*To whom correspondence should be addressed.

\begin{abstract}
Monotonic and fully reversed strain-controlled cyclic deformation experiments were conducted on a ZK60 magnesium (Mg) alloy in as-extruded and T5 aged conditions in ambient air. It was observed that the aging process had a significant influence on the stress-strain response and the fracture stress and strain under both monotonic tension and monotonic compression but a marginal influence on the stabilized cyclic deformation and fatigue of the material. An Electron Backscatter Diffraction (EBSD) analysis revealed that double twins were formed under a large compression strain in the as-extruded $\mathrm{Mg}$ but were not observed in the aged state under monotonic compression. A kink point in the strain-life fatigue curve demarcates the influence of twinning-detwinning deformation on fatigue. No twinning occurred throughout the fatigue life of the material when the strain amplitude was lower than the kink point value. With a strain amplitude slightly above the kink point, twinning-detwinning occurred but the process diminished as the loading cycle increased. The aging process enhanced the kink point slightly from a strain amplitude of $0.32 \%$ to $0.35 \%$. Only small amount residual twins were observed in the material after fatigue loading when the strain amplitudes were lower than $4 \%$.
\end{abstract}

Keywords: Aging effect, Cyclic deformation, Fatigue, ZK60 magnesium alloy 


\section{Introduction}

Magnesium (Mg) alloys offer a great potential application in automobile and aerospace structures and structural components in electronics and other consumer goods because of the low density, high specific strength, and excellent recyclability [1-2]. Heat treatments such as solid solution and artificial aging provide an effective way to improve the mechanical properties of $\mathrm{Mg}$ alloys. Recent investigations attempted to explore the effect of the heat treatment on the micro-structures and mechanical properties of Mg alloys [3-5].

Artificial aging can improve the mechanical properties of $\mathrm{Mg}$ alloys effectively by introducing precipitates. Mg-Zn based alloys, such as ZK60, are the most commonly used high strength commercial $\mathrm{Mg}$ alloys. They have two main kinds of precipitate phases: $\beta^{\prime}\left(\mathrm{Mg}_{4} \mathrm{Zn}_{7}\right.$ or $\left.\mathrm{Mg}_{2} \mathrm{Zn}_{3}\right)$ and $\beta^{\prime \prime}\left(\mathrm{MgZn}_{2}\right)$ [6-7]. It is generally accepted that the rod-like $\beta^{\prime}$ phase with its long axis normal to the basal plane provides a dominant strengthening effect. A plate-like $\beta^{\prime \prime}$ phase which forms parallel to the basal plane can be also seen, but it has been observed to contribute only a small portion to the total precipitate volume [8-10]. Bhattacharjee et al. [11] studied the effect of $\mathrm{Zr}$ addition on the precipitation of $\mathrm{Mg}-\mathrm{Zn}$ based alloys. It was suggested that with low-temperature aging such as that at $160^{\circ} \mathrm{C}, \mathrm{Zr}$ addition did not alter the precipitate phases and their morphologies. The only effect of $\mathrm{Zr}$ addition was to stabilize the $\beta$ phase at the elevated temperature by partitioning in it.

Work has been done to investigate the effect of $\mathrm{Mg}-\mathrm{Zn}$ precipitates on the monotonic deformation of Mg-Zn based alloys [4,12-15]. Chen and co-workers [12] studied the effect of T5 treatment on the tensile mechanical properties of ZK60. Stanford and Barnett [15] studied the monotonic deformation behavior of $\mathrm{Mg}-5 \% \mathrm{Zn}$ after different precipitation treatments. The experimental results revealed that the $\mathrm{Mg}-\mathrm{Zn}$ based alloys were aging hardenable. The boundaries between the precipitate phases and the $\mathrm{Mg}$ matrix can block dislocation slips to provide a strengthening effect. Furthermore, investigations were conducted on the effect of precipitates on individual slip systems and twin modes [6,8,15-17]. Stanford and Barnett [15] pointed out that in Mg-5Zn alloys, precipitation hardened the prismatic slips and (10-12) twin systems more than the basal slip. Robson et al. [17] also suggested that the rod-shaped precipitates in a Mg-5Zn alloy promoted twin nucleation but suppressed twin growth, and the process led to an increase in the number of twins.

In the last decade, investigations were made to understand the cyclic deformation behavior and low-cycle fatigue (LCF) of different wrought Mg alloys. The Mg alloys studied include extruded AZ31 [18-31], extruded AZ31B [32-42], extruded AZ61 [43-50], extruded ZK60 [51-55], rolled AZ31 [56-63], rolled AZ31B [64-65], rolled AZ91 [66-68], extruded AM30 [69-72], extruded AM50 [73], and extruded AM60 [74]. Major factors influencing the fatigue properties of Mg alloys include the material manufacturing process [25,36,74], strain amplitude [18-21, 
26,28,35,42,47,51,54,55,69,71], strain ratio [56,70], strain rate [24,39], stress ratio [24,67], material anisotropy [29,45,46,57-60,62,64,72], pre-strain [30,31,61,63], heat treatment [23,24,50], and environment [48,49]. Conventional wrought Mg alloys such as AZ31, AM30, and ZK60 have a strong basal texture with their $c$-axes approximately normal to the extrusion or rolling direction. Under monotonic loading, the wrought $\mathrm{Mg}$ alloys exhibit a pronounced tension-compression deformation asymmetry. During cyclic plastic deformation of the wrought Mg alloys, basal slip dominates the plastic deformation at smaller strain amplitudes and twinning-detwinning plays an important role at larger strain amplitudes [43,44,47,51,54,69]. Xiong et al. [54] reported that under fully reversed strain controlled cyclic deformation of extruded ZK60, three distinguishable types of cyclic deformation can be identified by different plastic deformation mechanisms: slip dominated, partial twinning-detwinning, and twinning-detwinning exhaustion. The strain-life fatigue curves display a detectable transition from lower strain amplitudes to higher strain amplitudes, forming two demarcation kink points [55].

ZK60 is a high strength commercial Mg alloy which has potential applications in the load-bearing components. Most of the existing work has been focused on extruded ZK60 for the high-cycle fatigue properties [75-78] and the LCF properties [51-55]. Mg alloys used for load-bearing applications are often heat treated. Therefore, it is important to understand the effect of aging treatment on the cyclic deformation and fatigue of $\mathrm{Mg}$ alloys. No work has been done so far on the effect of aging treatment on the cyclic deformation and LCF of the extruded ZK60 alloy.

The present work focuses on the monotonic deformation, cyclic deformation, and LCF of an extruded ZK60 Mg alloy with the aging effect. A detailed analysis of the stress-plastic strain hysteresis loops and EBSD microscopic characterizations are conducted near the kink point in the strain-life curve demarcating the influence of sustainable twinning-detwinning deformation.

\section{Material and experiment}

\subsection{Material and specimen}

A Mg alloy with a composition of $\mathrm{Mg}-6.0 \% \mathrm{Zn}-0.5 \% \mathrm{Zr}$ (wt\%) (ZK60) was prepared from commercially obtained pure $\mathrm{Mg}$ (99.95\%), pure $\mathrm{Zn}$ (99.9\%), and Mg-30\% Zr (wt\%) master alloy. A billet with a diameter of $260 \mathrm{~mm}$ was prepared by semi-continuous casting. The billet was extruded to a bar with a diameter of $75 \mathrm{~mm}$ at $360^{\circ} \mathrm{C}$ and an extrusion ratio of 12:1. ED and RD denote the extrusion direction and the radial direction of the cylindrical bar, respectively. TD is the direction perpendicular to the plane containing ED and RD. Part of the material was artificially aged at $175^{\circ} \mathrm{C}$ for 16 hours (T5). In the subsequent discussions, the hot-extruded ZK60 will be referred to as "as-extruded" and the material after the aging process will be referred to as "aged." 


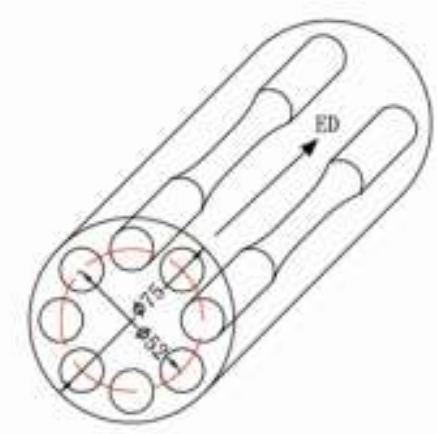

(a)

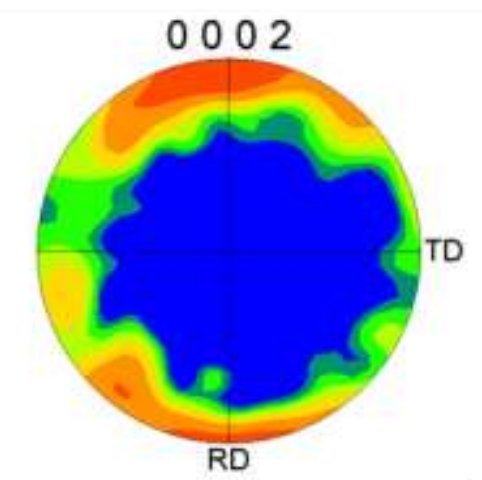

(c)

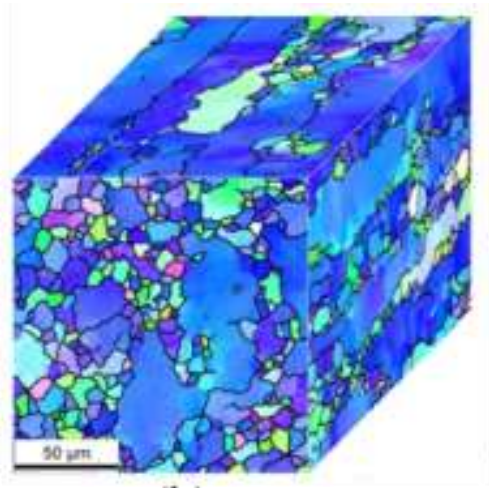

(b)
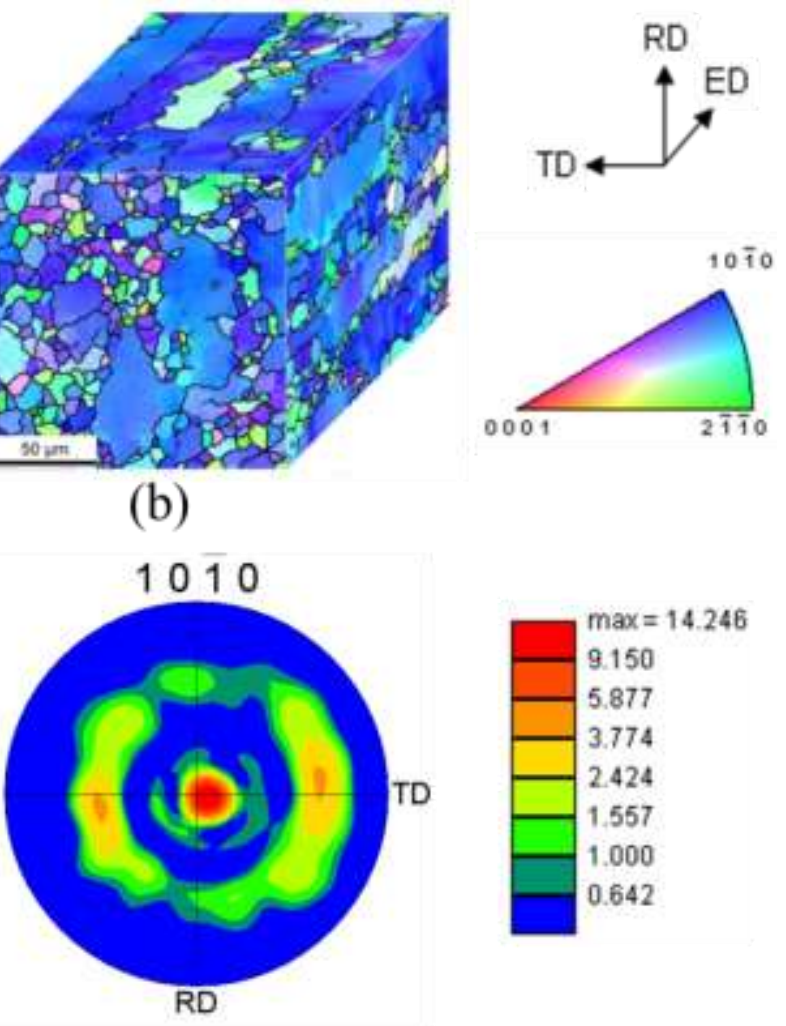

Fig. 1. Extruded ZK60: (a) testing specimens cut from extruded bar, (b) three dimensional stereography of initial microstructure measured by EBSD, (c) pole figures of initial material measured by EBSD.

As shown in Fig. 1a, testing specimens were cut from the 75mm-diameter extruded bar with their axes parallel to the extrusion direction. Eight testing specimens distribute uniformly on a circle with a diameter of $52 \mathrm{~mm}$. Initial microstructures of the as-extruded ZK60 were examined by electron back-scattered diffraction (EBSD) with TSL OIM data acquisition and analysis software package on the three planes normal to ED, RD and TD. The EBSD samples were taken at the location where the testing specimens were cut. Fig. 1b shows the three dimensional stereography of the EBSD orientation maps with an inverse pole figure map in the ED. The microstructure consists of a mixture of small and large elongated grains. On the RD-TD plane, small recrystallized equiaxed grains have an average size of $10 \mu \mathrm{m}$ and a large unrecrystallized grain can have a size over $50 \mu \mathrm{m}$. It is generally accepted that the equiaxed grains on the RD-TD plane are formed by dynamic recrystallization (DRX) during the extrusion process, while the large elongated grains represent the deformed state of the initial cast microstructure [79,80]. Results shown in Fig.1b reveal that the large unrecrystallized grains are oriented mainly with their $<10-10>$ 
directions parallel to the extrusion direction (blue color), while most of the small recrystallized grains have their $\langle 2-1-10\rangle$ directions parallel to ED (green color). Yi et al. [80] suggested that $<2-1-10>$ was a preferred orientation for the nucleation and growth of the recrystallized grains during the annealing treatment after extrusion, and the process led to a texture transition from $\langle 10-10\rangle$ to $\langle 2-1-10\rangle$. During hot extrusion, air cooling at the extrusion die exit is a similar procedure to the static annealing treatment $[79,80]$. Furthermore, microstructure evolution by discontinuous dynamic recrystallization during extrusion is comparable to static recrystallization [79]. No twins are found in the initial microstructure of the as-extruded ZK60 Mg alloy.

The (0002) and (10-10) pole figures presented in Fig. 1c show that the as-extruded ZK60 exhibits a typical basal texture with the $c$-axes of most of the grains perpendicular to ED. EBSD scans conducted on the aged ZK60 state confirms that the aging process did not alter the grain size and texture.

\subsection{Experiments}

Monotonic and cyclic loading experiments were conducted using a servo-hydraulic tension-torsion load frame in ambient air. The testing system is equipped with computer control and data acquisition. It has a capacity of $\pm 222 \mathrm{kN}$ in the axial load. For monotonic loading experiments, an extensometer with a gage length of $12.7 \mathrm{~mm}$ and a range of $\pm 40 \%$ was attached to the gage section of the specimen to measure the axial strain. For the strain-controlled cyclic experiments, an extensometer with a gage length $12.7 \mathrm{~mm}$ and a range of $\pm 10 \%$ was used.

Monotonic tension and compression experiments were conducted at a strain rate of $1.33 \times 10^{-2} / \mathrm{s}$ to obtain the static mechanical properties. Both the monotonic tension and compression experiments were conducted until the specimens were fractured into two parts. For fully reversed strain-controlled experiments, the strain amplitude ranges from $5 \%$ to $0.28 \%$, and the loading frequency ranges from $0.05 \mathrm{~Hz}$ to $10 \mathrm{~Hz}$ dependent on the strain amplitude. The fatigue life is defined by a $5 \%$ drop of the load from the stabilized or positive peak value. The microstructure of the specimens after monotonic and cyclic loading was examined by EBSD. A cylindrical sample was cut from the gage section of the testing specimen for EBSD scans. The EBSD sample was taken in the area a few millimeters away from the fracture surface. Automatic EBSD scans were performed with TSL data acquisition software on an area of $150 \mu \mathrm{m} \times 150 \mu \mathrm{m}$ with a step size ranging from $0.15 \mu \mathrm{m}$ to $0.3 \mu \mathrm{m}$. The EBSD data was analyzed using TSL OIM software.

\section{Experimental results and discussion}

\subsection{Monotonic tension and monotonic compression}

Fig. 2a presents the stress-strain curves from testing the as-extruded and aged ZK60 alloys under monotonic tension and monotonic compression. In order to compare the compression 
results with the tension properties, the compressive stress and strain are reported in their absolute values. The initial parts of the stress-plastic strain curves were magnified and are shown in Fig. 2b. The plastic strain is defined as the total true strain subtracted by the elastic strain which is equal to the stress divided by the elasticity modulus. The static mechanical properties of both as-extruded and aged ZK60 along ED are presented in Table1. Unless otherwise specified, the true stress and the true strain are reported and discussed through the current work.

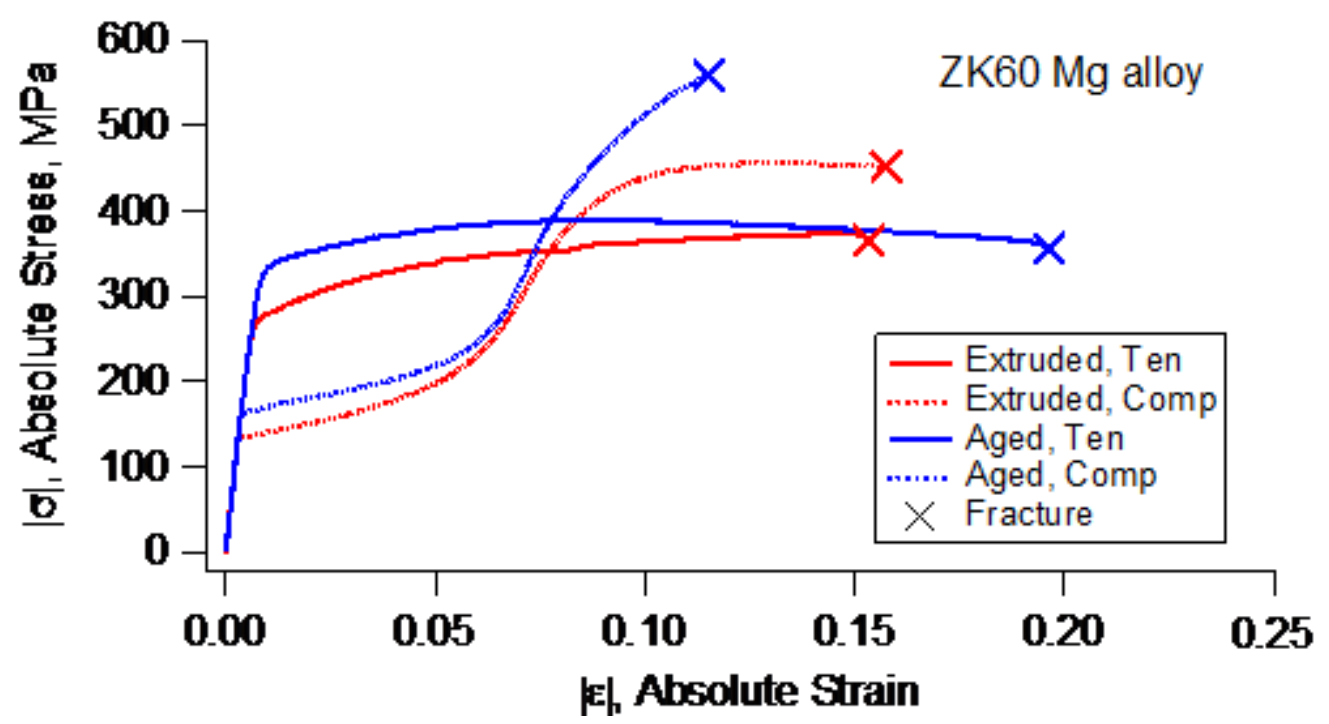

(a)

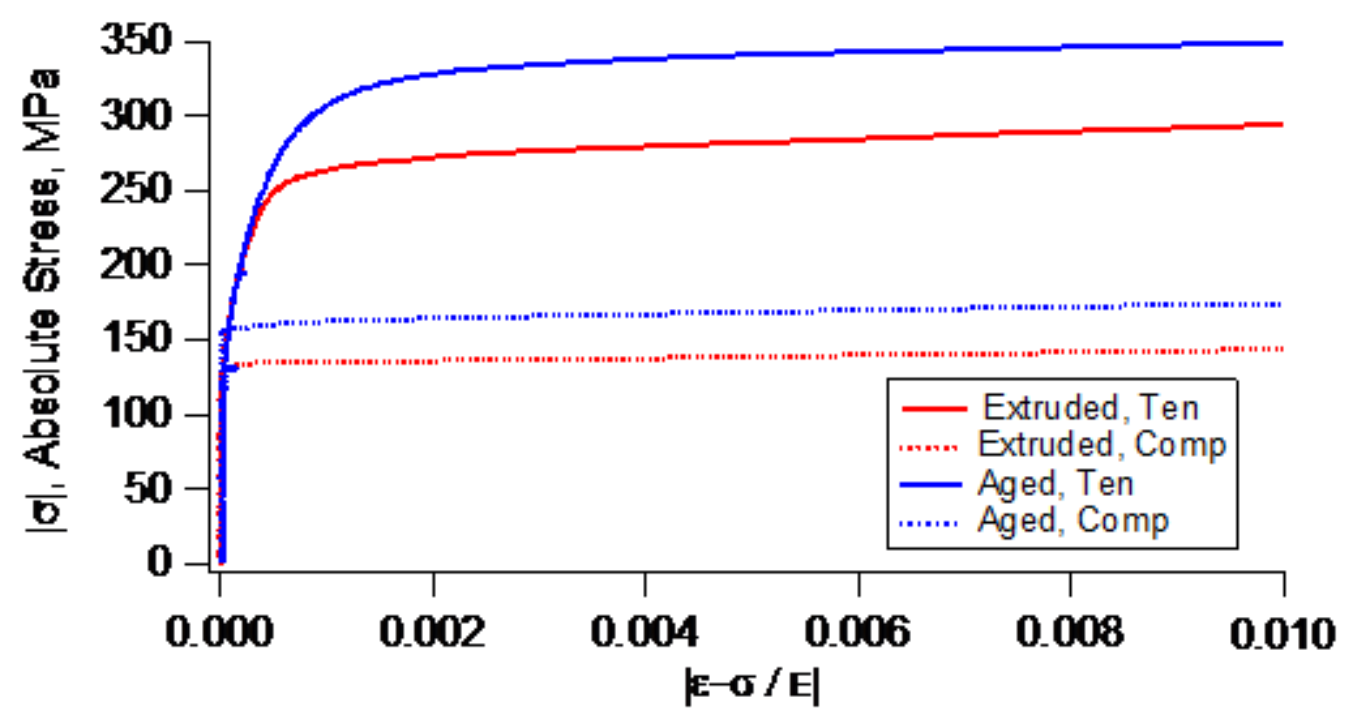

(b)

Fig. 2. Stress-strain curves of ZK60 Mg alloys under monotonic tension and compression: (a) stress-strain curves, (b) stress-plastic strain curves. 
Table 1

Static mechanical properties of ZK60 Mg alloy along the extrusion direction

\begin{tabular}{lll}
\hline & As-extruded & Aged \\
Elasticity modulus, $E$ & $44.4 \mathrm{GPa}$ & $44.9 \mathrm{GPa}$ \\
$0.2 \%$-offset yield stress in tension, $\sigma_{y t}$ & $273 \mathrm{MPa}$ & $329 \mathrm{MPa}$ \\
$0.2 \%$-offset yield stress in compression, $\sigma_{y c}$ & $136 \mathrm{MPa}$ & $165 \mathrm{MPa}$ \\
Ultimate strength under tension, $S_{u t}$ & $330 \mathrm{MPa}$ & $362 \mathrm{MPa}$ \\
Ultimate strength under compression, $S_{u c}$ & $524 \mathrm{MPa}$ & $624 \mathrm{MPa}$ \\
Fracture stress under tension, $\sigma_{f t}$ & $364 \mathrm{MPa}$ & $351 \mathrm{MPa}$ \\
Fracture stress under compression, $\sigma_{f c}$ & $451 \mathrm{MPa}$ & $560 \mathrm{MPa}$ \\
Elongation under tension, $e_{f t}$ & $16.7 \%$ & $21.7 \%$ \\
Elongation under compression, $e_{f c}$ & $14.5 \%$ & $10.9 \%$ \\
Reduction in area under tension, $R A$ & $21.84 \%$ & $31.95 \%$ \\
Twinning yield stress under compression, $\sigma_{t w}$ & $134 \mathrm{MPa}$ & $158 \mathrm{MPa}$ \\
\hline
\end{tabular}

The stress-strain curves of both as-extruded and aged ZK60 exhibit a pronounced tension-compression asymmetry due to the strong basal texture formed by the extrusion process (Fig.2a). Due to basal texture, tension twins can be easily activated under compression but difficult to activate under tension. Such a directional nature of twinning leads to the observed tension-compression deformation asymmetry.

The monotonic stress-strain curves of both the extruded and aged Mg can be divided into three regimes: elastic deformation, microyielding, and macroyielding plastic deformation. Microyielding under both monotonic tension and compression is most likely due to the activation of basal slip in favorably oriented grains [51,54,81-83]. For the same material, the microyielding stress under tension is identical to that under compression. A careful observation of Fig. $2 b$ and the stress-plastic strain curves of the first reversals of several fatigue testing specimens reveals that microyielding is initiated at a stress of approximately $100 \mathrm{MPa}$ for both as-extruded and aged ZK60, indicating no influence of the aging process on microyielding.

The strengthening effect of $\mathrm{Mg}-\mathrm{Zn}$ precipitates due to aging can be seen in the macroyielding stress. Under monotonic tension, macroyielding is mainly due to the activation of prismatic non-basal <a> slip. Under monotonic compression, macroyielding is associated with the activation of tension twins [8,83-86]. As shown in Fig.2, the 0.2\%-offset yield stress under tension is $273 \mathrm{MPa}$ for as-extruded ZK60 and the value is $329 \mathrm{MPa}$ for aged ZK60. The $0.2 \%$-offset yield stresses under compression are $136 \mathrm{MPa}$ and 165MPa for as-extruded and aged ZK60, respectively. The aging treatment enhances the tension macroyielding stress by $56 \mathrm{MPa}$ and the compression macroyielding stress by $29 \mathrm{MPa}$.

Another strengthening effect of precipitates is reflected by the enhanced ultimate strength in 
the aged state. The aging treatment improves the tensile ultimate strength slightly (from $330 \mathrm{MPa}$ to $362 \mathrm{MPa}$ ) and the compression ultimate strength dramatically (from 524MPa to 624MPa) (Table 1). The aging process enhances the elongation under tension (from as-extruded $16.7 \%$ to $21.7 \%$ for aged) but decreases the elongation under compression from $14.5 \%$ for as-extruded to $10.9 \%$ for aged state. It should be noticed that the ultimate strength and elongation are nominal stress and nominal strain, respectively, while the results presented in Fig.2 are true stresses and true strains.
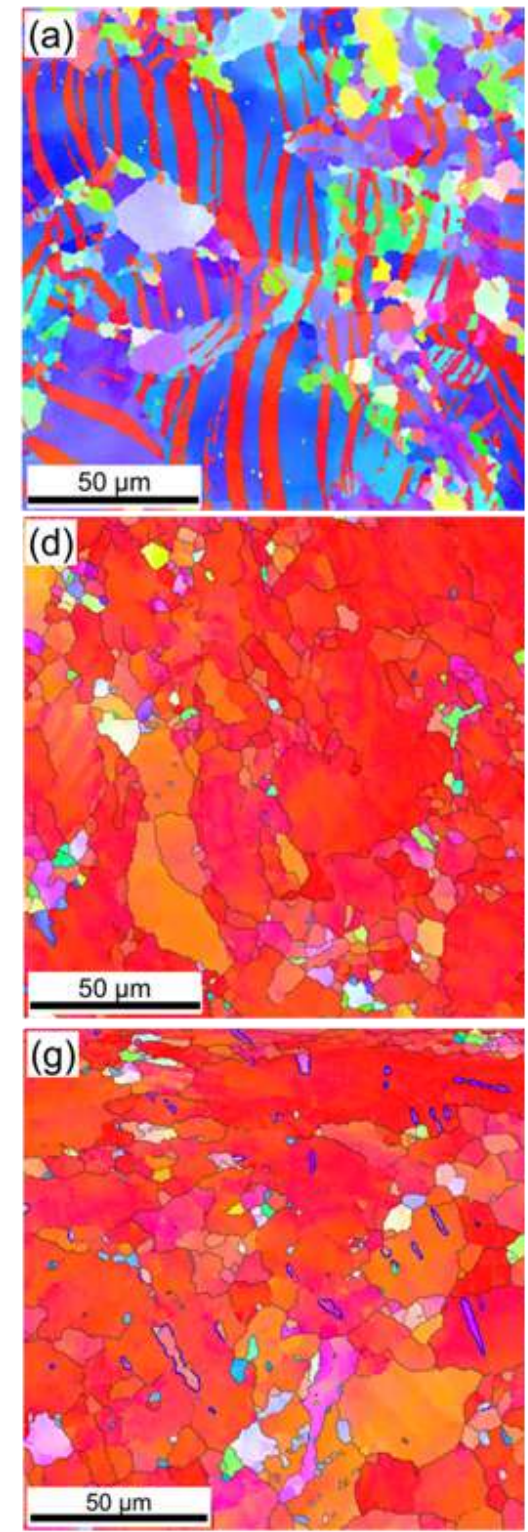
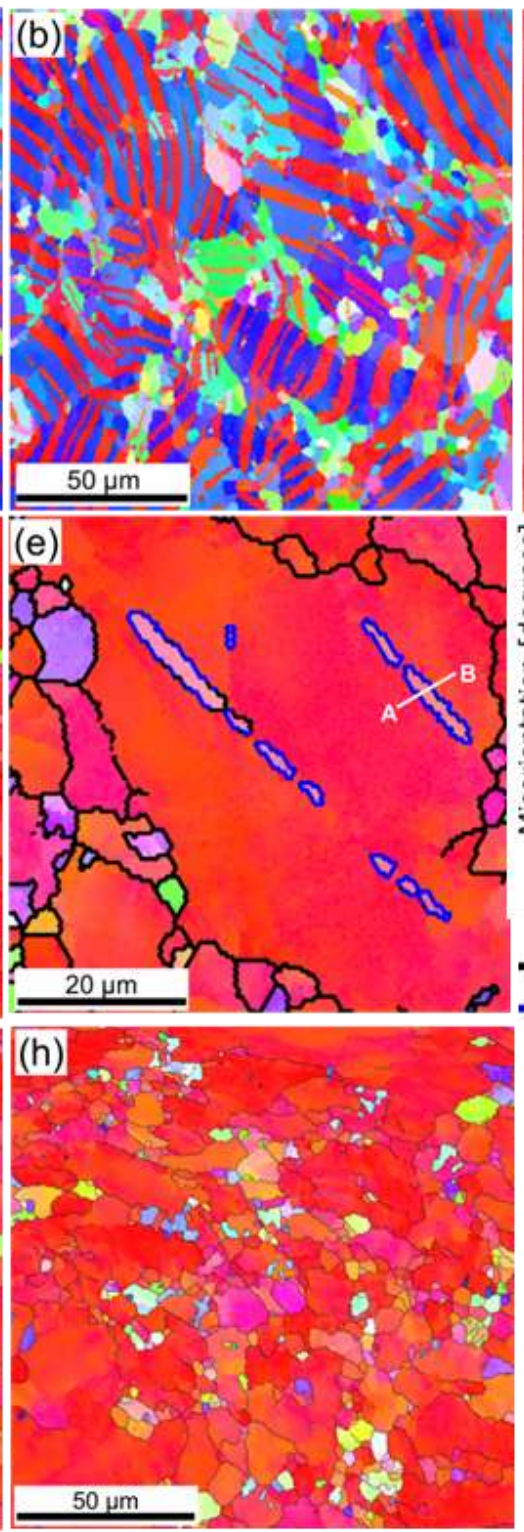
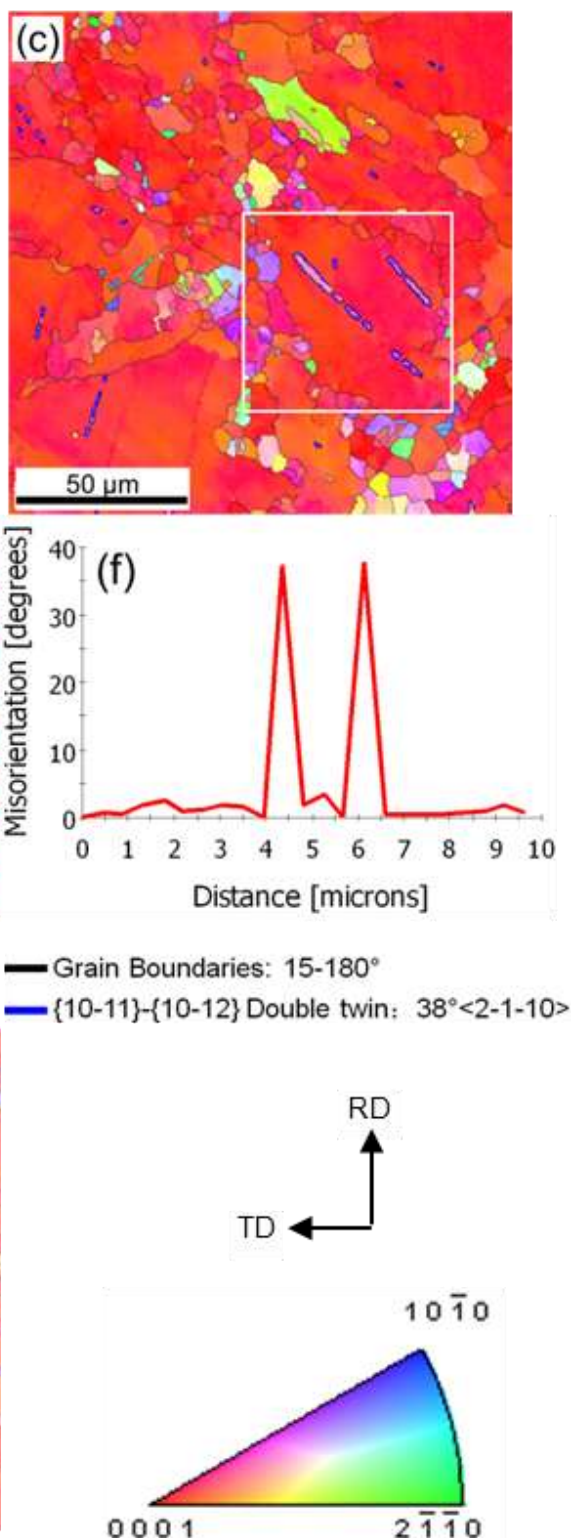

Fig. 3. Microstructures measured by EBSD for as-extruded and aged ZK60 under monotonic compression at different strains: (a) 4\% compression of as-extruded, (b) 4\% compression of aged, (c) $10 \%$ compression of as-extruded, (d) 10\% compression of aged, (e) enlarged local area in (c) to show double twins, (f) point to point misorientations along line A-B in (e), (g) after compression fracture of as-extruded, (h) after compression fracture of aged ZK60. 
In order to understand the aging effect on deformation twin, EBSD scans were conducted at compression strains of $4 \%$ and $10 \%$ and after fracture under monotonic compression for both as-extruded and aged ZK60. As shown in Fig.3a and Fig.3b for the two conditions of ZK60 after a compressive strain of $4 \%$, large bulk tension twins can be seen and these twins are observed mainly in the large unrecrystallized grains that were oriented with their $\langle 10-10\rangle$ directions parallel to the ED in the original state. The (10-12) tension twin volume fractions of as-extruded and aged ZK60 are $29 \%$ and 39\%, respectively, after $4 \%$ compressive strain. The increased twin fraction in the aged state is possibly due to the local stress concentrations around precipitates that may enhance initiation of twinning [5,17].

It was reported [54] that after a compression strain of $7.1 \%$ in extruded ZK60, twinning process was exhausted and the matrix was dominated by tension twins. A majority of the matrix grains are reoriented by $86.3^{\circ}$, and this leads to a $c$-texture. With an increase in the compression strain, plastic deformation is accommodated by either (10-11) compression twins and/or non-basal slips which have a component of the Burgers vector in the $c$-axis direction. Compression twins reorient the $c$-texture grains by $56^{\circ}$ and (10-12) tension twining usually occurs within the compression twins simultaneously. Such a process leads to the so-called (10-11)-(10-12) double twins which reorient the $c$-axis by $38^{\circ}$ [87-90]. The formation of double twins facilitates the complex shuffle required at the tip of the growing (10-10) compression twin [90, 91].

Fig. 3c and Fig.3d show the microstructure of as-extruded and aged ZK60, respectively, after a compression strain of $10 \%$. Fig. 3e is a magnified plot of the white rectangular area in Fig. 3c, and Fig. $3 \mathrm{f}$ is the point to point misorientation distribution along line AB in Fig. 3e. As shown in Fig.3e, two kinds of boundaries are marked in the EBSD IPF map: the dark lines represent the large-angle grain boundaries and the blue lines represent the boundaries generated by (10-11)-(10-12) double twins which have a misorientation $38^{\circ}$ about the rotation axis $\langle 2-1-10\rangle$. It can be seen that after 10\% monotonic compression strain, some (10-11)-(10-12) double twins are formed in as-extruded ZK60 (see Fig.3c and e), as being marked by the blue lines using OIM software and confirmed by the $38^{\circ}$ misorientation shown in Fig. 3f. These double twins are found only in the large unrecrystallized grains. However, for aged ZK60 (Fig.3 d), no double twins are observed.

Fig. $3 \mathrm{~g}$ and Fig.3h show the EBSD results after fracture under monotonic compression. For as-extruded ZK60, more (10-11)-(10-12) double twins are observed than after 10\% compression strain. For aged ZK60, no (10-11)-(10-12) double twins are detectable by EBSD even after fracture under compression. This indicates that the aging treatment can hinder (10-11)-(10-12) double twins during monotonic compression after the basal textured matrix is swallowed by the (10-12) tension twins. For aged ZK60, the precipitates may suppress the growth of (10-10) 
compression twins and the subsequent (10-12) tension twins. Another possibility is that the (10-11)-(10-12) double twins in the aged specimen are too small to be observed by using EBSD. It was reported $[87,88]$ that due to the fine size of $(10-10)$ compression twins and the high dislocation density within the compression twins, it would be difficult to index the compression twins by EBSD. Dedicated microscopic observations such as TEM are required to further explore the role of the $\mathrm{Mg}-\mathrm{Zn}$ precipitates in the aged $\mathrm{Mg}$ to possibly suppress compression twins.

\subsection{Cyclic deformation under fully reversed strain-controlled loading}

Fig. 4 shows the stress-strain hysteresis loops obtained from fully reversed strain-controlled cyclic loading experiments with strain amplitudes ranging from $4 \%$ to $0.7 \%$ for both as-extruded and aged ZK60. In order to show the evolution of the hysteresis loops with respect to loading cycles, the stress-strain hysteresis loops of the first 10 cycles, the cycle at a quarter fatigue life, and the cycle at half fatigue life are presented for a selected strain amplitude. The stress-strain hysteresis loops corresponding to half fatigue lives are taken to be the stabilized hysteresis loops for fully reversed strain-controlled cyclic loading under the present investigation, and they are shown in Fig. 5 for both as-extruded and aged ZK60. The evolution of the stress amplitudes and the mean stress with the number of loading cycles for both as-extruded and aged ZK60 are summarized in Fig.6.

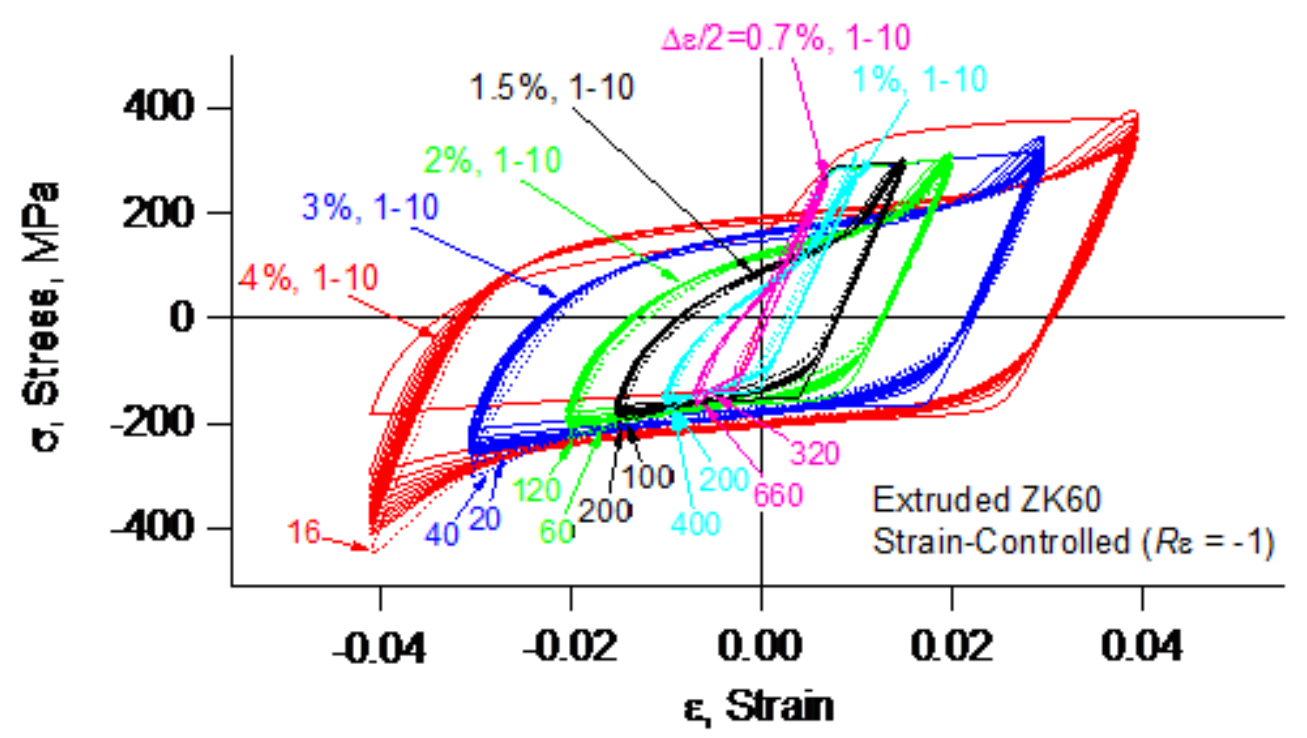

(a) 


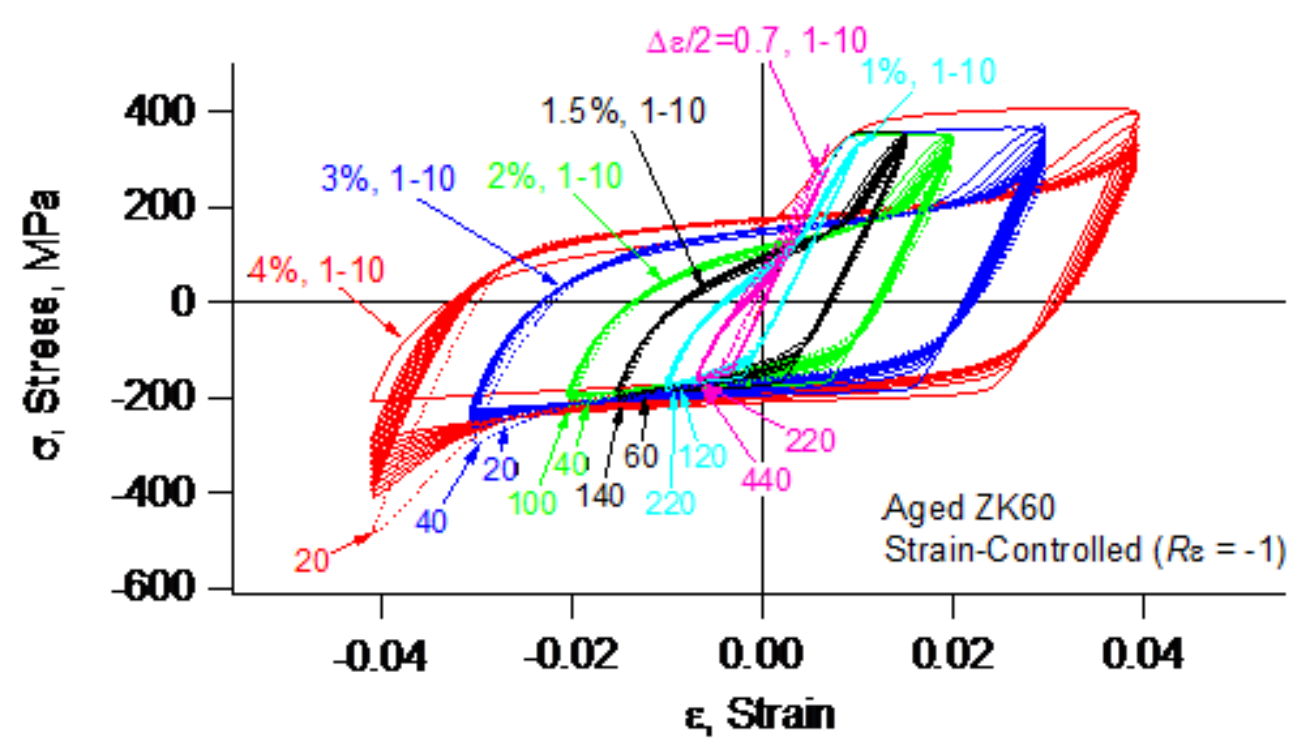

(b)

Fig. 4. Cyclic stress-strain hysteresis loops obtained from fully reversed strain-controlled experiments: (a) as-extruded ZK60; (b) aged ZK60.

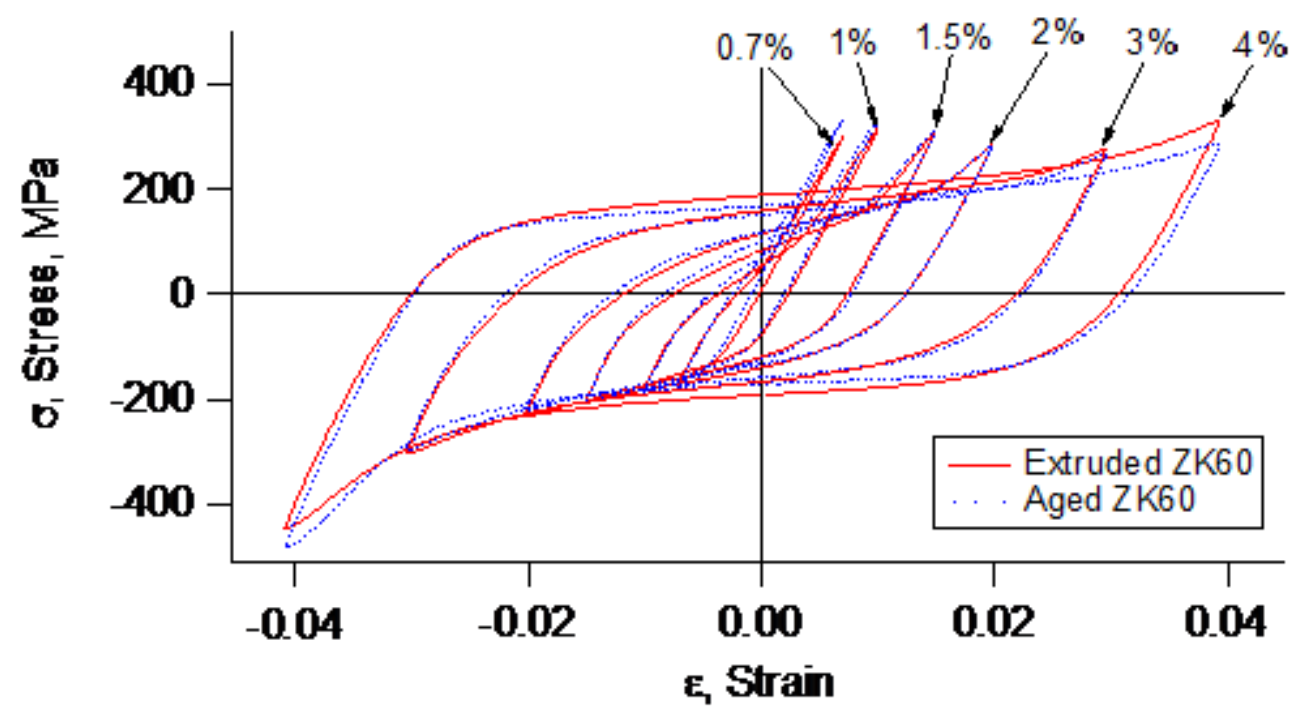

Fig. 5. Stabilized stress-strain hysteresis loops obtained for as-extruded and aged ZK60 


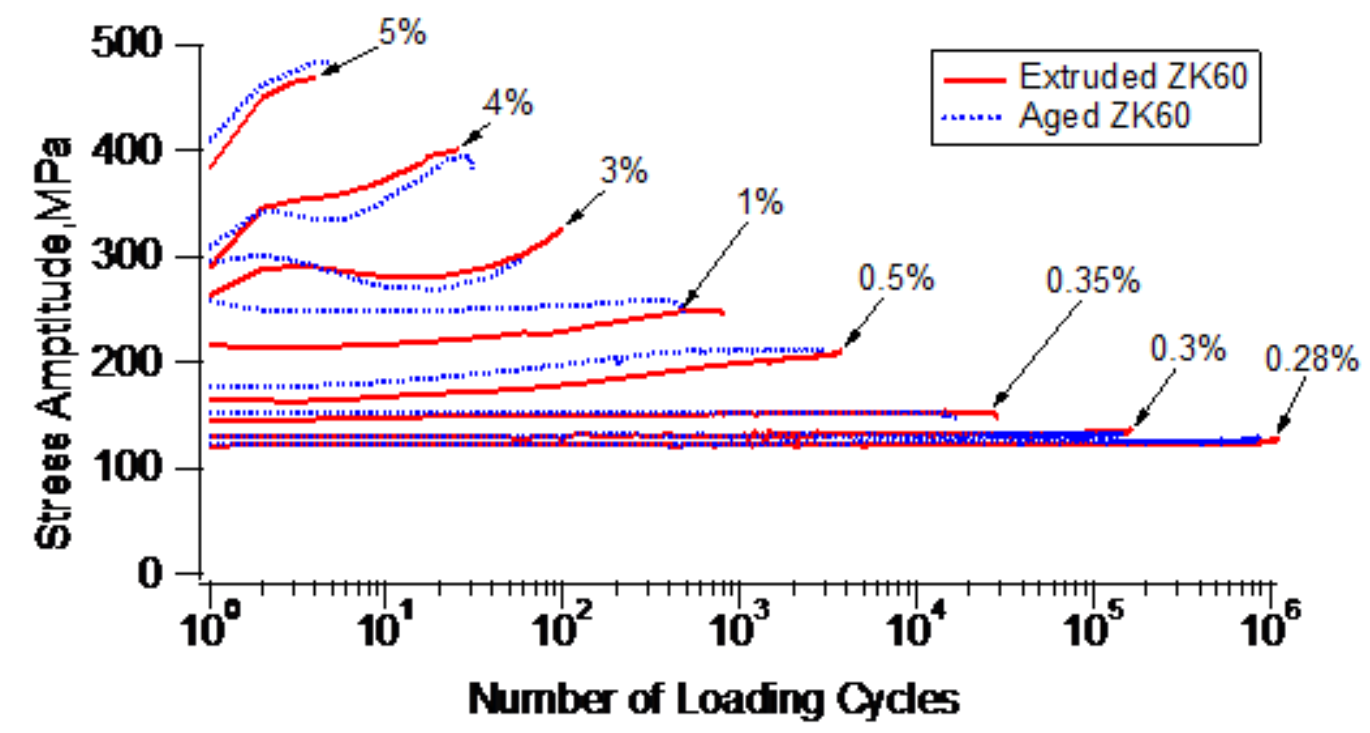

(a)

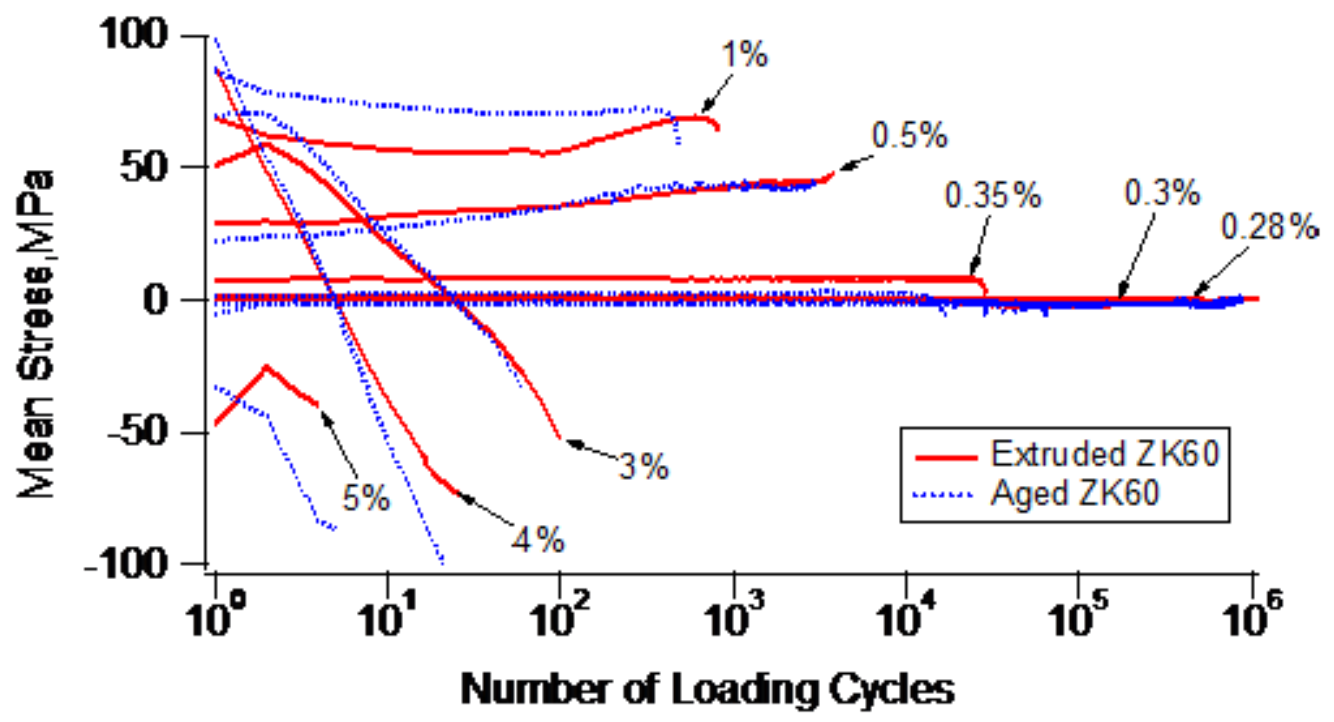

(b)

Fig. 6. Variations of stress amplitude and mean stress with the number of loading cycles for as-extruded and aged ZK60

From the results shown in Figs. 4-6, it can be found that for both as-extruded and aged ZK60, when the strain amplitude is between $1.5 \%$ and $4 \%$, twinning is exhausted in the compressive reversal and non-basal slip occurs. Detwinning is completed in the tensile reversal and non-basal slip occurs near the end of the loading reversal. Both the compressive reversal and tensile reversal exhibit a sigmoidal shape. With increasing strain amplitudes, a more and more symmetric stress-strain hysteresis loop shape is observed. An increase in the stress amplitude 
with the loading cycles shown in Fig. 6 is an indication of cyclic hardening. The mean stress decreases quickly with increasing loading cycles when the strain amplitude is larger than $1.5 \%$. When the strain amplitudes are between $0.7 \%$ and $1 \%$, partial twinning-detwinning is involved in the plastic deformation: twinning is not exhausted in the compressive reversal and detwinning is completed in the tensile reversal. Only the tensile reversal shows a sigmoidal shape and the hysteresis loop shows an asymmetric shape with a positive mean stress.

From Fig. 6, it can be seen that when the strain amplitudes are larger than or equal to $0.35 \%$, the stress amplitudes of aged ZK60 is larger than that of as-extruded ZK60 in the first few loading cycles, but they tend to become practically identical as the loading cycles increase.

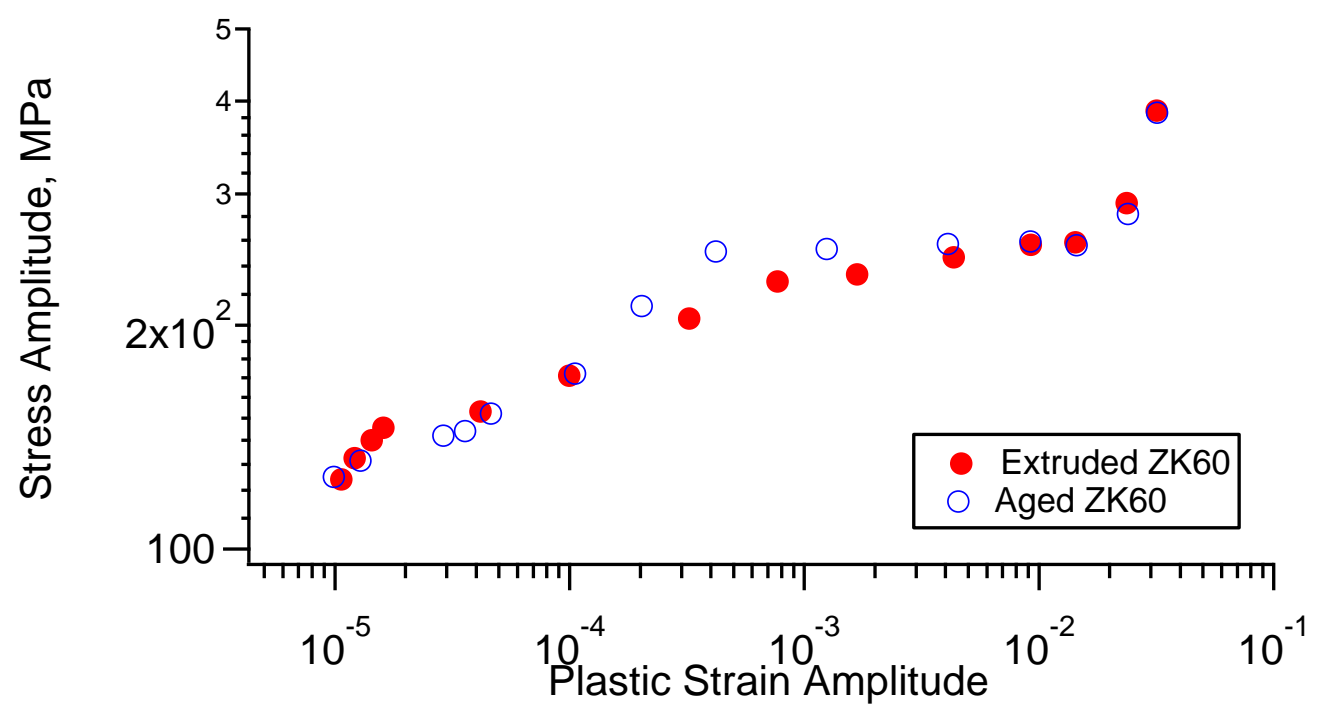

Fig. 7. Cyclic stress-plastic strain curves for as-extruded and aged ZK60

Fig. 7 presents the cyclic stress-plastic strain curve (CSPSC) for as-extruded and aged ZK60. The CSPSC is the relationship between the stabilized stress amplitude and the stabilized plastic strain amplitude. It should be noticed that the CSPSC for both as-extruded and aged ZK60 have a plateau region which indicates an independence of the stabilized stress amplitude of the strain amplitude.

Results shown in Figs.4-7 lead to the following observations on the influence of the aging process. When the strain amplitude is smaller than $0.35 \%$, the cyclic deformation of as-extruded is identical to that of the aged. When the strain amplitude is higher, the stress-strain response under cyclic loading of the two states of the material differs only in the early stage of cyclic loading. The stabilized stress-strain hysteresis loops of as-extruded ZK60 are practically the same as these of aged ZK60. This is further confirmed by the results shown in Fig.7 for the CSPSCs of the two states of the Mg alloys. 


\subsection{Fatigue}

The fatigue results of the as-extruded and aged ZK60 obtained from fully reversed strain controlled tension-compression experiments along the extrusion direction are listed in Table 2 and Table 3, respectively. The stabilized stress amplitude and the mean stress reported in Table 2 and Table 3 are taken from the stress-strain hysteresis loops at approximately half fatigue lives.

\section{Table 2}

Fatigue results for as-extruded ZK60 alloy obtained from fully reversed strain-controlled tension-compression fatigue experiments along extrusion direction.

\begin{tabular}{cccccrc}
\hline Spec ID & $\begin{array}{c}\Delta \varepsilon / 2 \\
(\%)\end{array}$ & $\begin{array}{c}f \\
(\mathrm{~Hz})\end{array}$ & $\begin{array}{c}\sigma_{\mathrm{m}} \\
(\mathrm{MPa})\end{array}$ & $\begin{array}{c}\Delta \sigma / 2 \\
(\mathrm{MPa})\end{array}$ & $\begin{array}{c}N_{\mathrm{f}} \\
(\mathrm{cycle})\end{array}$ & $\begin{array}{c}\Delta W^{p} \\
\left(\mathrm{MJ} / \mathrm{m}^{3}\right)\end{array}$ \\
\hline ZK2B31 & 5.0 & 0.05 & -25.4 & 450.0 & 3 & 41.53 \\
ZK2D71 & $-4.0^{*}$ & 0.06 & -58.6 & 388.1 & 31 & 25.29 \\
ZK2B33 & 3.0 & 0.075 & -12.8 & 291.3 & 100 & 15.24 \\
ZK2B17 & 2.0 & 0.125 & 26.3 & 258.0 & 230 & 7.384 \\
ZK2B38 & 1.5 & 0.2 & 51.3 & 256.1 & 400 & 4.112 \\
ZK2B14 & 1.0 & 0.33 & 67.6 & 246.5 & 820 & 1.571 \\
ZK2B28 & 0.7 & 0.5 & 64.8 & 233.5 & 1,320 & 0.5462 \\
ZK2A11 & 0.6 & 0.75 & 75.0 & 229.0 & 1,854 & 0.2535 \\
ZK2B15 & 0.5 & 1.0 & 44.4 & 203.8 & 3,820 & 0.1072 \\
ZK2B35 & 0.4 & 2.0 & 22.9 & 171.1 & 13,050 & 0.0159 \\
ZK2B27 & 0.35 & 2.5 & 8.1 & 153.2 & 29,760 & 0.0119 \\
ZK2B37 & 0.33 & 4.0 & 2.5 & 145.5 & 48,200 & 0.0074 \\
ZK2B32 & 0.32 & $2.5 / 5.0$ & 2.1 & 139.9 & 105,000 & 0.0030 \\
ZK2D82 & 0.30 & $1.0 / 5.0$ & -1.9 & 132.6 & 183,860 & 0.0026 \\
ZK2D81 & 0.28 & $1.0 / 10.0$ & 0.4 & 124.0 & $>1,115,300$ & -- \\
\hline \multicolumn{1}{c}{ \& strain amplitude, $f=$ frequency, $\Delta \sigma / 2=$ stabilized stress amplitude, $\sigma_{m}=$ stabilized } \\
mean stress, $\Delta W^{p}=$ plastic strain energy density per loading cycle, $N_{f}=$ Number of cycles to \\
failure. *a negative sign for a strain amplitude denotes that the experiment started with \\
compression reversal.
\end{tabular}




\section{Table 3}

Fatigue results for aged ZK60 alloy obtained from fully reversed strain-controlled tension-compression fatigue experiments along extrusion direction.

\begin{tabular}{cccccrc}
\hline Spec ID & $\begin{array}{c}\Delta \varepsilon / 2 \\
(\%)\end{array}$ & $\begin{array}{c}f \\
(\mathrm{~Hz})\end{array}$ & $\begin{array}{c}\sigma_{\mathrm{m}} \\
(\mathrm{MPa})\end{array}$ & $\begin{array}{c}\Delta \sigma / 2 \\
(\mathrm{MPa})\end{array}$ & $\begin{array}{c}N_{\mathrm{f}} \\
(\mathrm{cycle})\end{array}$ & $\begin{array}{c}\Delta W^{p} \\
\left(\mathrm{MJ} / \mathrm{m}^{3}\right)\end{array}$ \\
\hline ZK3B31 & 5.0 & 0.05 & -44.3 & 462.9 & 4 & 40.09 \\
ZK3A12 & $-4.0^{*}$ & 0.06 & -96.2 & 384.8 & 32 & 23.30 \\
ZK3B37 & 3.5 & 0.07 & -75.6 & 334.5 & 48 & 18.95 \\
ZK3B32 & 3.0 & 0.075 & -14.9 & 281.5 & 74 & 14.96 \\
ZK3B14 & 2.0 & 0.125 & 31.0 & 251.4 & 192 & 7.381 \\
ZK3B61 & 1.5 & 0.2 & 51.2 & 259.2 & 280 & 4.449 \\
ZK3B13 & 1.0 & 0.33 & 71.8 & 257.1 & 480 & 1.747 \\
ZK3B17 & 0.7 & 0.75 & 78.6 & 252.8 & 900 & 0.5082 \\
ZK3B66 & 0.6 & 0.75 & 67.7 & 251.0 & 1,740 & 0.1839 \\
ZK3B15 & 0.5 & 1.0 & 42.7 & 212.0 & 2,960 & 0.0769 \\
ZK3B33 & 0.4 & 2.0 & 10.0 & 171.9 & 12,400 & 0.0143 \\
ZK3B18 & 0.35 & 2.5 & 2.5 & 152.4 & 18,000 & 0.0133 \\
ZK3B36 & 0.34 & 2.0 & -2.8 & 149.3 & 25,050 & 0.0108 \\
ZK3B38 & 0.33 & 2.5 & -1.4 & 144.0 & 46,700 & 0.0093 \\
ZK3B35 & 0.32 & 2.5 & -7.4 & 141.8 & 54,350 & 0.0063 \\
ZK3B16 & 0.30 & $3.0 / 5.0$ & -1.8 & 131.7 & 151,500 & 0.0024 \\
ZK3A72 & 0.28 & $1.0 / 10.0$ & -1.5 & 125.0 & $>868,700$ & -- \\
\hline
\end{tabular}

$\Delta \varepsilon / 2=$ strain amplitude, $f=$ frequency, $\Delta \sigma / 2=$ stabilized stress amplitude, $\sigma_{m}=$ stabilized mean stress, $\Delta W^{p}=$ plastic strain energy density per loading cycle, $N_{f}=$ Number of cycles to failure. $*^{*}$ a negative sign for a strain amplitude denotes that the experiment started with compression reversal.

Fig. 8 shows the strain-life curves of as-extruded and aged ZK60. Each point in Fig. 8 represents one fatigue experiment. An arrow at the data point denotes a run-out experiment. The strain-life curve can be divided into three segments reflecting different failure mechanisms. The following three-parameter equation is used to describe each segment of the strain-life curve:

$$
\left(\frac{\Delta \varepsilon}{2}-\varepsilon_{0}\right)^{\xi} N_{f}=C
$$

where $\Delta \varepsilon / 2$ is the strain amplitude and $N_{f}$ is the number of cycles to failure. The remaining three parameters $\varepsilon_{0}, \xi$ and $C$ are constants obtained by best fitting the experimental data. The dotted lines in Fig. 8 are the factor-of-two fatigue life boundaries. 


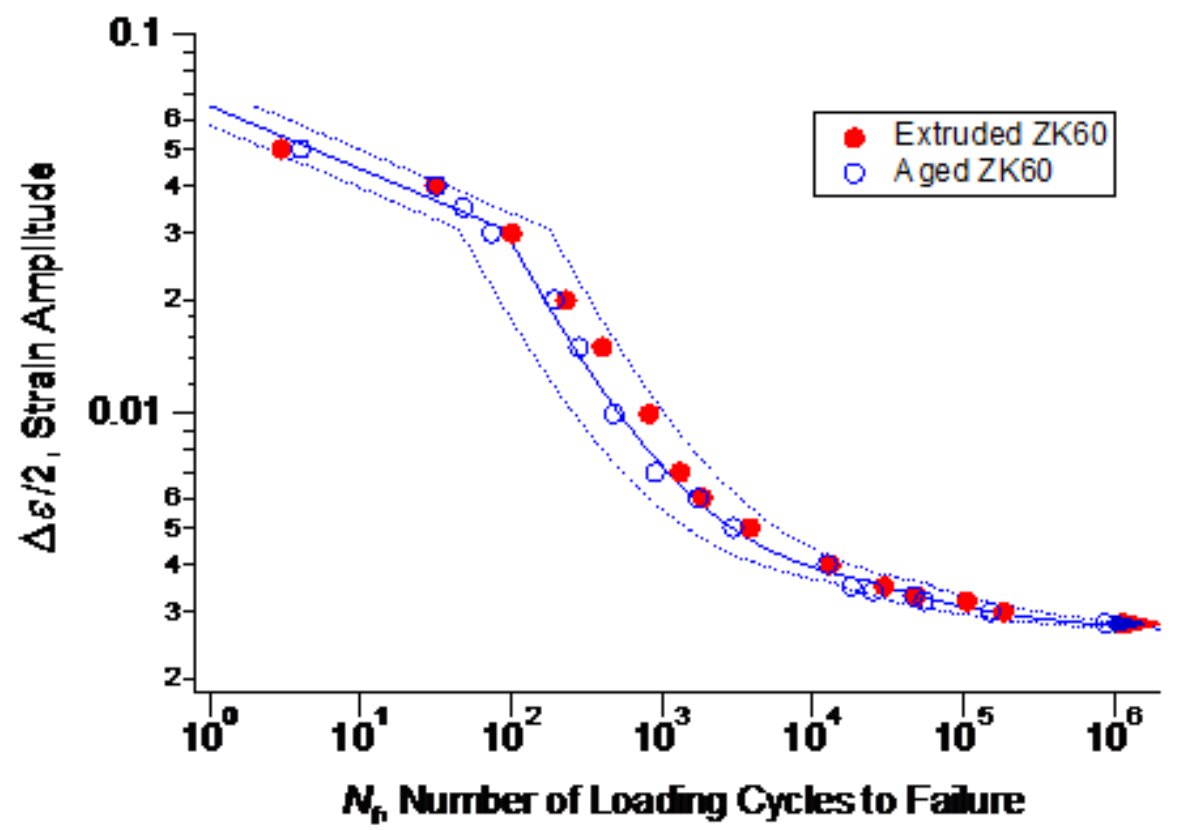

Fig. 8. Strain-life curves for as-extruded and aged ZK60

It was reported that for AZ31B [42], AZ61 [47], ZK60 [51], and GW83 [95] Mg alloys there exists a kink point in the strain-life curve. When the strain amplitudes are above this kink point, twinning-detwinning deformation is a significant plastic deformation mechanism in the cyclic deformation, and when the strain amplitudes are below this kink point, dislocation slips dominate the plastic deformation. From Fig. 8 it can be seen that such a kink point exists for both as-extruded and aged ZK60. The strain amplitudes corresponding to this kink point are $0.32 \%$ and $0.35 \%$, respectively, for as-extruded and aged ZK60.

There exists another clear kink point in the strain-life curve at the very low cycle fatigue regime. As shown in Fig. 8, when the strain amplitudes are larger than 3\% for both as-extruded and aged ZK60, the strain amplitudes and fatigue lives display an approximate linear relationship in $\log -\log$ scale. The fatigue specimens with strain amplitudes larger than $3 \%$ were finally fractured due to compression in the last loading cycle. The final fatigue failure of the specimens subjected to a large strain amplitude is due to the exhaustion of the compression strength of the material similar to the material under monotonic compression. Such a fatigue failure under uniaxial loading is different from a common observation where fatigue cracks are initiated and grow till fracture occurs under tension. A detailed discussion about the fatigue fracture at different strain amplitudes can be found in an earlier publication for a similar material [55].

Consistent with the observation of similar cyclic deformation in as-extruded and aged ZK60, the fatigue properties of the two conditions of ZK60 are also similar as shown in Fig.8. When the strain amplitudes are below $0.35 \%$, the fatigue lives of as-extruded ZK60 and aged ZK60 are 
practically identical. When the strain amplitude is between $0.35 \%$ and $3 \%$, the fatigue life of aged ZK60 is slightly shorter than that of as-extruded ZK60 for the same strain amplitude. When the strain amplitude is larger than 3\%, no practical distinction can be made between the two states of the material in the strain-life curve.

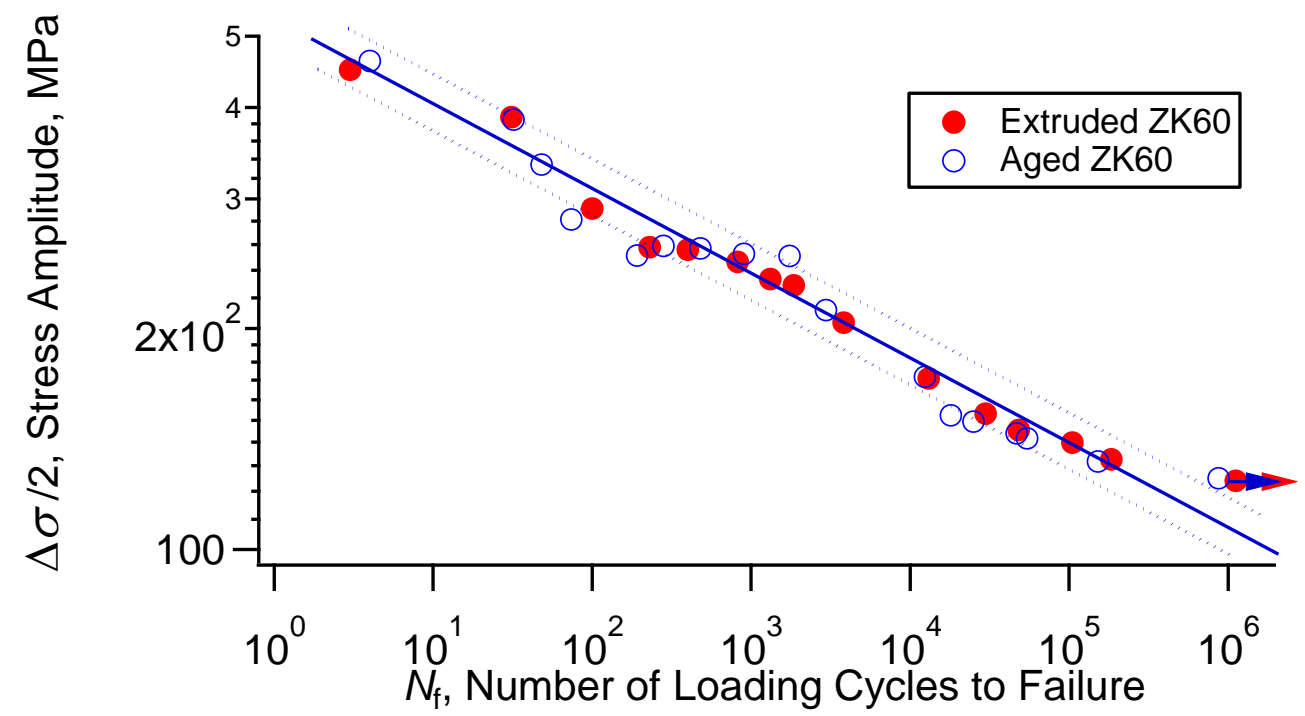

Fig. 9. Stress-life curves for as-extruded and aged ZK60

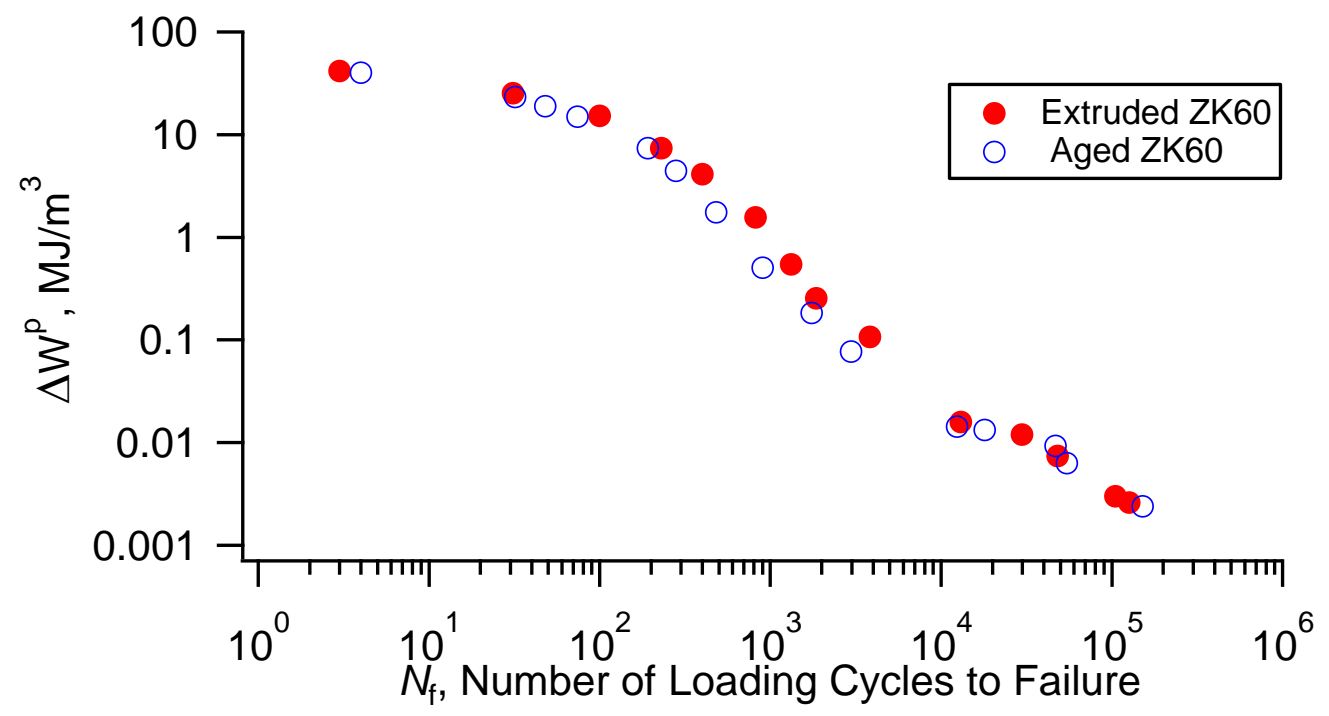

Fig. 10. Plastic strain energy density per loading cycle and fatigue life for as-extruded and aged ZK60 Mg alloys

The similarity in fatigue between aged and as-extruded ZK60 can be also seen in Fig. 9 which is a stress-life fatigue curve and Fig. 10 which is a plot of the relationship between the plastic strain energy density per loading cycle as a function of fatigue life. The results shown in the two figures 
further confirm that overall the aging process has a marginal influence on the fatigue properties of extruded ZK60. A note needs to be made with respect to the lines in Fig.9. The solid straight line reflects a power law relationship for the log-log plot and the dotted lines are the factor-of-two fatigue life boundaries. Although most of the date points in Fig.9 fall within the factor-of-two lines, a careful examination of the data reveals that the tendency of the stress-life curve does not appear to be linear in the log-log scale. It is rather an " $\mathrm{S}$ " shaped curve. There is a clear plateau in the stress-life curve at a stress amplitude of $250 \mathrm{MPa}$ which corresponds to a fatigue life ranging from 200 to 2,000 loading cycles for aged ZK60. Such a plateau is consistent with that in the cyclic stress-plastic strain curve shown in Fig.7 for the same material.

\subsection{Detailed material deformation behavior in the neighborhood near the lower kink point in the} strain-life curve

The lower kink point in the strain-life curve represents a demarcation line above which twinning-detwinning plays an important role in the cyclic deformation [54,55]. In order to explore further the strain amplitude associated with the kink point, the evolution of the stress-plastic strain hysteresis loops and EBSD characterization are analyzed in the strain amplitude region near the kink point. The plastic strain is defined as follows :

$$
\varepsilon_{p}=\varepsilon-\frac{\sigma}{E}
$$

where,

$$
E=E_{0}(1-\sigma / b)
$$

In Eq.(2) and Eq.(3), $\varepsilon_{p}$ is the plastic strain, $\varepsilon$ and $\sigma$ are the true strain and true stress, respectively, $E$ is the elasticity modulus, $b$ is a material constant for nonlinear elasticity of the material, and $E_{0}$ is the elasticity modulus at the origin of the stress-strain curve. Nonlinear elasticity needs to be considered in order to better analyze the stress-plastic strain response for small strain amplitude loading. A simple linear dependence of the elasticity modulus on the applied stress (Eq.(3)) was adopted for considering the nonlinear elasticity of the material. For the $\mathrm{Mg}$ alloy under investigation, $b=20,000 \mathrm{MPa}$ provides a good description of the nonlinearity. Eq.(3) is similar to a nonlinear elasticity consideration for a high strength bearing steel [96]. It should be noticed that the consideration of nonlinear elasticity only affect the analysis of plastic deformation at a very small strain amplitude. 

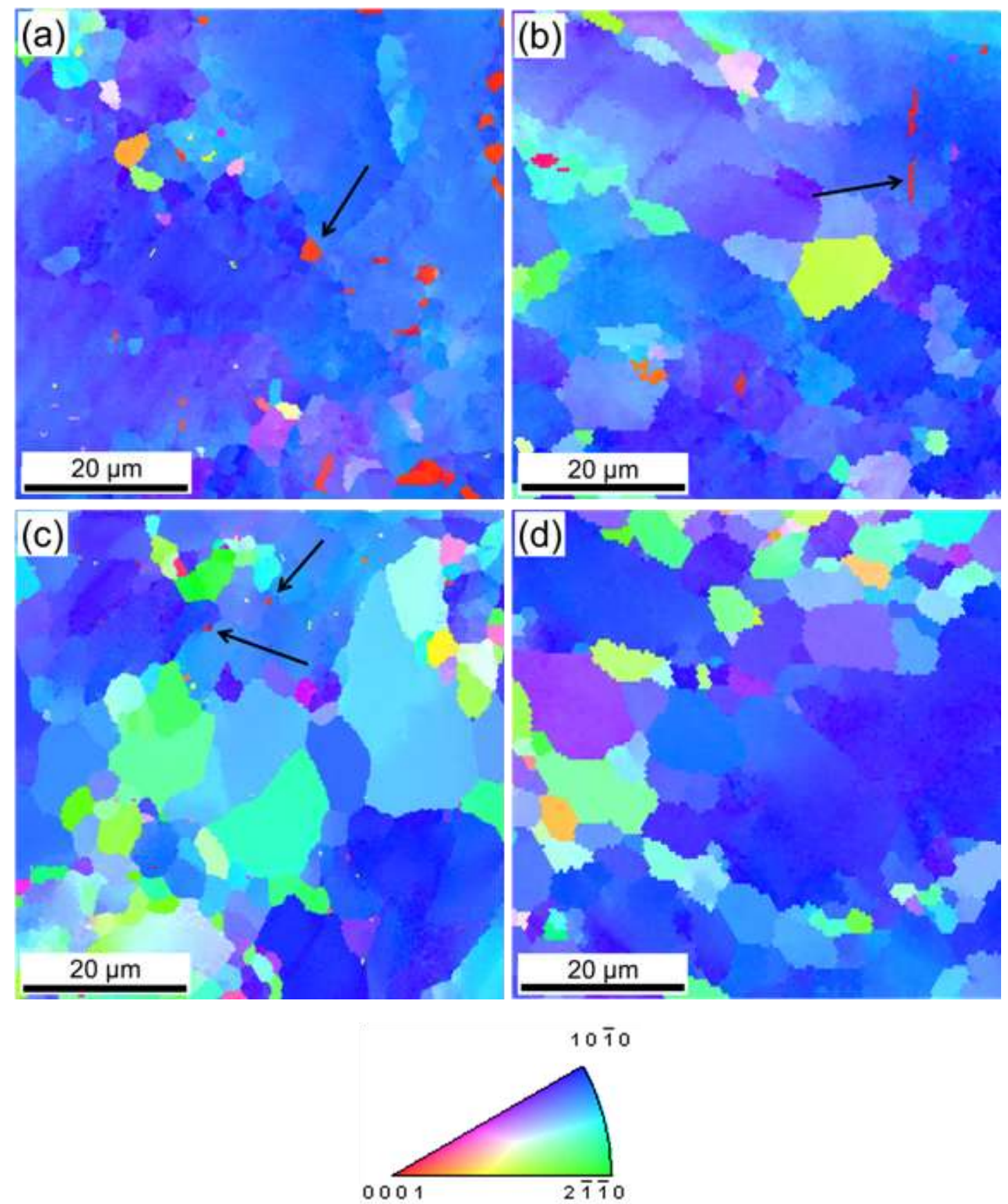

Fig. 11. Microstructures measured by EBSD of the as-extruded specimens after cyclic deformation at different strain amplitudes: (a) $4 \%$ after 21 loading cycles, (b) $1 \%$ after fatigue failure, (c) $0.4 \%$ after fatigue failure, (d) $0.32 \%$ after fatigue failure

Fig. 11 shows the EBSD scans of the as-extruded ZK60 specimens after cyclic deformation at strain amplitudes of $4.0 \%, 1.0 \%, 0.4 \%$, and $0.32 \%$. The observation surface is perpendicular to the extrusion or the loading direction. For a testing specimen with a fatigue crack, the EBSD 
sample was taken within the gage section of the testing specimen a few millimeters away from the fatigue crack. The cyclic deformation experiment at a $4 \%$ strain amplitude was terminated at the $21^{\text {st }}$ cycle after the completion of the positive peak strain. The fatigue life at $4 \%$ strain amplitude is approximately 31 cycles (Table 1 ). The other three experiments were terminated after fatigue fracture which occurred after a tensile loading reversal. Therefore, all the four samples for the EBSD scans shown in Fig.11 were subjected to a complete detwinning process in their last loading cycles.

For a basal-textured $\mathrm{Mg}$, a compressive stress may result in tension twinning and a subsequent tensile load leads to detwinning. Residual twins in a basal-textured $\mathrm{Mg}$ refer to the twins left in the material subjected to cyclic loading after the completion of the tensile loading reversal in a loading cycle. A glance at the results shown in Fig.11 reveals that a higher strain amplitude results in more residual twins. However, insignificant residual twins accumulate with loading cycles for fully reversed strain-controlled loading. The twin volume fraction is approximately $3 \%$ for a high strain amplitude of $4 \%$ after two thirds of the fatigue life. Small measurable residual twins were detected in the sample after fatigue at $0.4 \%$ strain amplitude. No residual twins were observed in the material after fatigue failure at a strain amplitude of $0.32 \%$. The OIM software confirms that all the detected residual twins shown in Fig.11 are tension twins. The EBSD results shown in Fig. 11 suggest that for fully reversed strain-controlled cyclic loading, most of the twins formed during the compressive loading reversal are detwinned during the tensile loading reversal even the strain amplitude is as high as $4.0 \%$. There is little accumulation of residual twins detectable by EBSD.

Twinning-detwinning is an important cyclic deformation process. A relationship between the twinning-detwinning process and the shape of the stress-strain hysteresis loops can be explored in the neighborhood near the lower kink point in the strain-life fatigue curve. Fig.12 shows the evolution of the stress-plastic strain hysteresis loops at two strain amplitudes near the kink point. The stress-plastic strain response allows for a close observation of the shape of the hysteresis loops. Due to the limit in the strain measurement accuracy using an extensometer and the small plastic strain for the $0.32 \%$ strain amplitude case, a few data points with large noises were eliminated in the stress-strain loops presented in Fig.12(b) for a better understanding of the general tendency of the phenomenon. The limited noise reduction was applied only to the case of $0.32 \%$ strain amplitude. 


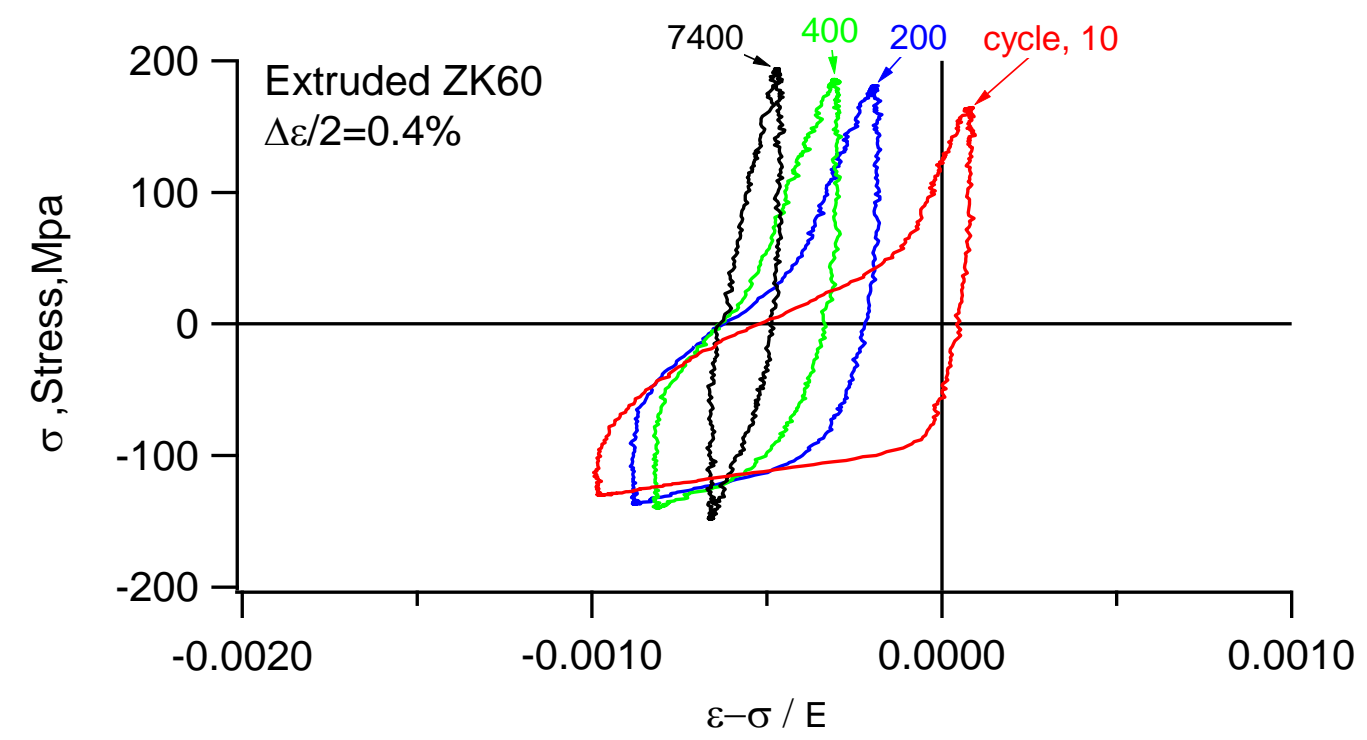

(a)

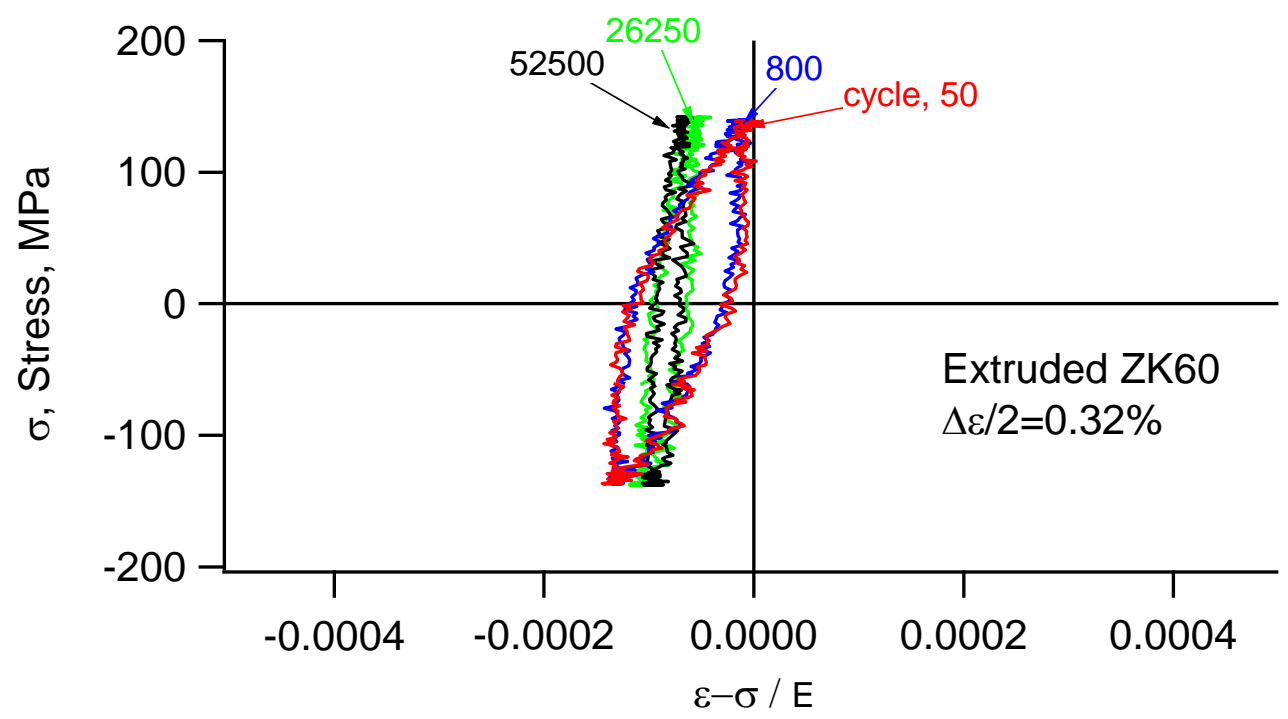

(b)

Fig. 12. Stress-plastic strain hysteresis loops of as-extruded ZK60 at two strain amplitudes: (a) $0.4 \%$; (b) $0.32 \%$.

At a strain amplitude of $0.4 \%$ during initial cyclic deformation, such as the $10^{\text {th }}$ loading cycle, the stress-plastic strain hysteresis loops exhibit a typical asymmetric shape which can be attributed to the unexhausted twinning in the compressive reversal and complete detwinning in the tensile reversal (Fig.12a). With increasing number of loading cycles, the hysteresis loop tends to become more and more symmetry. When the number of the loading cycles reaches 7,400 (half of the fatigue life), the hysteresis loop becomes almost fully symmetric with the upper branch of the 
stress-plastic strain hysteresis loop being identical to that of the lower branch. The symmetric loops in the small strain amplitude of $0.4 \%$ can be attributed to the slip dominated plastic deformation mechanism after sufficient number of loading cycles at the loading amplitude. The evolution of the stress-plastic strain hysteresis loops of $0.4 \%$ strain amplitude indicates that twinning-detwinning occurs but the process diminishes as the loading cycle increases. As shown in Fig. 11c, small measurable residual twins can be detected in the material after fatigue fracture at $0.4 \%$ strain amplitude. These residual twins are generated in the early loading cycles and they are retained in the later part cyclic deformation. Despite the small amount of the trivial residual twins under $0.4 \%$ strain amplitude, twinning-detwinning can be confirmed to occur during the early stage of deformation.

When the strain amplitude is $0.32 \%$ (Fig.12b), the stress-plastic strain hysteresis loops are symmetric throughout the entire fatigue loading history. This indicates that twinning-detwinning does not occur under a strain amplitude of $0.32 \%$. From Table 1 it can be seen that the twinning yield stress under monotonic compression for as-extruded ZK60 is $134 \mathrm{MPa}$. The minimum stress under a strain amplitude of $0.32 \%$ for as-extruded ZK60 is very close to the twinning stress of the material (Table 2). Therefore, bulk twinning-detwinning cannot be activated at a strain amplitude less than $0.32 \%$. The EBSD result shown in Fig. 11d confirms that no residual twins were result in the microstructure of the specimen after fatigue failure at the $0.32 \%$ strain amplitude. Plastic deformation at $0.32 \%$ strain amplitude is solely due to basal dislocation slips.

A similar analysis of stress-plastic strain hysteresis loops was conducted for other strain amplitudes near the lower kink point in the strain-life curve for both as-extruded and aged ZK60. It can be determined that the lower kink point strain amplitudes are $0.32 \%$ and $0.35 \%$, respectively, for as-extruded and aged states. For strain amplitudes slightly above this kink point, the stress-plastic strain hysteresis loops are asymmetric in the initial stage of the cyclic deformation and become more and more symmetric as the loading cycle increases. For strain amplitudes below this kink point, the hysteresis loops are always symmetric and twinning-detwinning does not occur throughout the strain-controlled fatigue loading.

The aforementioned results and analysis provide a direct way to determine the lower kink point in the strain-life fatigue curve shown in Fig.8. For fully reversed strain-controlled loading of an extruded $\mathrm{Mg}$, the lower kink point in the strain-life curve corresponds to the bulk activation twinning stress, $\sigma_{t w}$. In other words, the strain amplitude at the lower kink point in Fig.8 is corresponding to the case where the minimum stress in a loading cycle has a value of $\sigma_{t w}$. An approximate determination of the kink point is $\sigma_{t w} / \mathrm{E}$ where $\mathrm{E}$ is the elasticity modulus. For the two materials under investigation, $\sigma_{t w}=134 \mathrm{MPa}$ for as extruded and $\sigma_{t w}=158 \mathrm{MPa}$ for aged. For a more precise determination of the lower kink point in the strain-life curve, nonlinear elasticity and occurrence of basal slips before bulk twinning should be considered. 
The discussion with regard to the lower kink point in the strain-life curve indicates that the activation of tension twins in $\mathrm{Mg}$ requires a certain level of stress. If the absolute value of the minimum stress during cyclic loading is lower than the twinning stress, $\sigma_{t w}$, of the material, bulk twinning may never occur. As a comparison, a carbon steel under a stress-controlled or strain controlled cyclic loading condition can display purely bulk elastic deformation during the initial part of cyclic loading and can develop significant cyclic plasticity after certain number of loading cycles $[97,98]$.

\section{Further Discussions}

The material used in the current investigation is slightly different from the extruded ZK60 alloys studied before [51,54,55]. A major difference is that the as-extruded ZK60 alloy under current investigation has a stronger basal texture intensity that leads to a lower twinning stress under monotonic compression $[54,55]$. Due to the similarity in alloying compositions and microstructures, the cyclic stress-strain curves and strain-life curves of the current ZK60 are similar to those investigated earlier $[54,55]$.

Aging process can induce Mg-Zn precipitates in the extruded ZK60 alloy. The boundaries between the precipitates and the $\mathrm{Mg}$ matrix can block dislocation slips to result in a strengthening effect. The main strengthening phase is the rod-like $\beta^{\prime}$ phase with its long axis normal to the basal plane. However, the strengthening effect of $\mathrm{Mg}-\mathrm{Zn}$ precipitates on individual deformation mechanism can be different. For the extruded ZK60 alloy under investigation, basal slips are responsible for microyielding and the aging process does not alter the microyielding stress. In contrast, macroyieding under tension is due to the activation of prismatic slips, and the aging process enhances the macroyielding stress in tension by $56 \mathrm{MPa}(20 \%$ increase). Macroyielding under compression is induced by tension twins and the aging process enhances twinning stress by $29 \mathrm{MPa}$, a $18 \%$ increase over the as-extruded. It is clear that the aging process improves the macroyieding stress and the twinning activation stress of the material. In other words, the $\mathrm{Mg}-\mathrm{Zn}$ precipitates formed in the aging process help prevent prismatic slips and tension twins from occurring but do not change the basal slip property of the material.

The fatigue experiments also provide evidence that $\mathrm{Mg}-\mathrm{Zn}$ precipitates formed in the aging process do not influence basal slips. When the strain amplitude is below the lower kink point in the strain-life curves $(0.32 \%$ for as-extruded and $0.35 \%$ for aged $)$, such as $0.3 \%$ and $0.28 \%$, the cyclic deformation, stress amplitudes (Fig. 6a), and the fatigue lives (Fig. 8) of the as-extruded ZK60 are identical to those of the aged condition. Noting that cyclic plastic deformation with strain amplitudes below the kink point is dominated by basal slips, the aging process does not have a strengthening effect on basal slips for ZK60 alloy. 
The observation of the influence of the $\mathrm{Mg}$ - Zn precipitates on plastic deformation of $\mathrm{ZK} 60 \mathrm{Mg}$ alloy is consistent with the consideration of the effect of particles on individual deformation mechanisms in a visco-plastic self-consistent (VPSC) model by Stanford and Barnett [15]. To describe the plastic deformation of a Mg-5Zn alloy, the VPSC model assumes that the precipitates harden prismatic slip systems more than the basal slip system due to a smaller inter-particle spacing and larger effective particle diameters on the prismatic plane than these on the basal plane [15]. The theory hypothesizes that because the tension twins require basal slips to accommodate the shape change, the precipitates harden the tension twins more than do the basal slips. In other words, the rod-like $\beta^{\prime}$ precipitates display a stronger strengthening effect on prismatic slips and tension twins than do the basal slips.

The precipitate phase boundaries can act as dislocation sinks similar to the grain boundaries [12]. During plastic deformation, dislocations slide to the high energy boundaries. However, the storage of dislocations can be balanced out by reorganization and annihilation of the dislocations on the grain boundaries and the precipitate phase boundaries [92]. The reorganization and annihilation do not benefit the storage of dislocations, which do not help sustain work hardening. Another possible influence of the aging treatment is the lower solute atom content in solid solution that increases the stacking fault energy [93] and enhances the dislocation cross slips and the climb ability. A lower solute atom content is expected to enhance dislocation recovery during plastic deformation at room temperature [94]. Due to the two aspects of influences of aging treatment, the aged ZK60 has a weaker dislocation storage ability than as-extruded ZK60 during plastic deformation [12]. As a result, during strain-controlled cyclic deformation at the first few loading cycles, the stress amplitudes of aged ZK60 are larger than these of the as-extruded ZK60 due to the strengthening effect of the $\mathrm{Mg}-\mathrm{Zn}$ precipitates. With increasing loading cycles, the as-extruded ZK60 exhibits a stronger dislocation storage ability which enhances cyclic hardening. The overall result is a similar stabilized stress-strain response between as-extruded and aged ZK60.

\section{Conclusions}

Monotonic and fully reversed strain-controlled cyclic deformation and fatigue experiments were conducted on as-extruded and aged ZK60 magnesium $(\mathrm{Mg})$ alloy along the extrusion direction. The following conclusions can be drawn from the experimental study:

1) The aging treatment $\left(175^{\circ} \mathrm{C}\right.$ for 16 hours (T5)) has a significant influence on static mechanical properties under both monotonic tension and monotonic compression. Double twins are produced after a large compressive strain in as-extruded ZK60 but not in aged ZK60.

2) Basal slip-dominated microyielding occurs at a stress of approximately $100 \mathrm{MPa}$ under both monotonic tension and monotonic compression. The aging process does not influence the microyielding of ZK60 Mg alloy. 
3) The lower kink point in the strain-life curve demarcates the influence of twinning-detwinning process in cyclic plastic deformation of a $\mathrm{Mg}$ alloy. This point is corresponding to the twinning stress under compression for extruded $\mathrm{Mg}$ alloy. The strain amplitudes at the kink points are $0.32 \%$ and $0.35 \%$, respectively, for ax-extruded and aged ZK60, indicating an influence of the aging process on the activation of tension twinning.

4) At strain amplitudes up to the lower kink point in the strain-life curve, cyclic deformation and fatigue of the as-extruded ZK60 Mg alloy are identical to those of aged. No residual twins can be found by EBSD in the microstructure after fatigue failure. This indicates that the aging process which introduces $\mathrm{Mg}-\mathrm{Zn}$ precipitates has no effect on basal slips of the $\mathrm{Mg}$ alloy.

5) For strain amplitudes larger than the lower kink point value, the aging treatment has an influence on cyclic deformation only in the early period of loading cycles. With increasing number of loading cycles, the stress amplitudes and hysteresis stress-strain loops of as-extruded ZK60 tend to become identical to those of the aged ZK60.

6) When the strain amplitudes are slightly above the kink point value, twinning-detwinning occurs but the process diminishes as the loading cycle increases. Insignificant residual twins can be found by EBSD in the microstructure after fatigue.

7) Under fully reversed strain-controlled fatigue loading, residual twins (twins left after the completion of the tensile loading reversal for the extruded $\mathrm{Mg}$ alloy loaded in the extrusion direction) measurable by using EBSD are insignificant for a strain amplitude up to 4\%. Most of the twins produced during the compressive loading reversal are detwinned in the tensile reversal during the entire fatigue loading history.

8) The aging treatment has marginal influence on fatigue properties of ZK60 alloy.

\section{Acknowledgements}

Jie Dong gratefully acknowledges the support by National Natural Science Foundation of China (U1360104), Shanghai Baosteel Group Corporation (50901045), and Shanghai Rising-Star Program (12QH1401200). Yanyao Jiang thanks supports by the US National Science Foundation (1126582), the US Department of Energy Office of Basic Energy Sciences (DE-SC0002144), and the National Natural Science Foundation of China (51275472).

\section{References}

[1] F.H. Froes, Mater. Sci. Eng. A 184 (1994) 119-133.

[2] B.L. Mordike, T. Ebert, Mater. Sci. Eng. A 302 (2001) 37-45.

[3] D.K. Xu, L.Liu, Y.B. Xu, E.H. Han, Mater. Sci. Eng. A 420 (2006) 322-332. 
[4] H. Chen, S.B. Kang, H. Yu, J. Cho, H.W. Kim, G. Min, J. Alloys Compd. 476 (2009) 324-328.

[5] S.R. Agnew, R.P. Mulay, F.J. Polesak III, C.A. Calhoun, J.J. Bhattacharyya, B. Clausen, Acta Mater. 61 (2013) 3769-3780.

[6] J.B. Clark, Acta Metall. 13 (1965) 1281-1289.

[7] J.F. Nie, Scr. Mater. 48 (2003) 1009-1015.

[8] J. Jain, P. Cizek, W.J. Poole, M.R. Barnett, Acta Mater. 61 (2013) 4091-4102.

[9] X. Gao, J.F. Nie, Scr. Mater. 56 (2007) 645-648.

[10] J. Buha, J. Alloys Compd. 472 (2009) 171-177.

[11] T. Bhattacharjee, C.L. Mendis, T.T. Sasaki, T. Ohkubo, K. Hono, Scr. Mater. 67 (2012) 967-970.

[12] X. Chen, F. Pan, J. Mao, J. Wang, D. Zhang, A. Tang, J. Peng, Materials and Design 32 (2011) 1526-1530.

[13] W. Liu, J. Dong, P. Zhang, Z. Yao, C. Zhai, W. Ding, J. Mater. Sci. 44 (2009) 2916-2924.

[14] D.K. Xu, L. Liu, Y.B. Xu, E.H. Han, Mater. Sci. Eng. A 420 (2006) 322-332.

[15] N. Stanford, M.R. Barnett, Mater. Sci. Eng. A 516 (2009) 226-234.

[16] J.D. Robson, N. Stanford, M.R. Barnett, Acta Mater. 59 (2011) 1945-1956.

[17] J.D. Robson, N. Stanford, M.R. Barnett, Scr. Mater. 63 (2010) 823-826.

[18] S. Hasegawa, Y. Tsuchida, H. Yano, M. Matsui, Int. J. Fatigue 29 (2007) 1839-1845.

[19] S. Begum, D.L. Chen, S. Xu, A.A. Luo, Int. J. Fatigue 31 (2009) 726-735.

[20] M. Huppmann, M. Lentz, S. Chedid, W. Reimers, J. Mater. Sci. 46 (2011) 938-950.

[21] S. H. Kwon, K. S. Song, K. S. Shin, S. I. Kwun, Met. Mater. Int. 17 (2011) 207-213.

[22] S.M. Yin, F. Yang, X.M. Yang, S.D. Wu, S.X. Li, G.Y. Li, Mater. Sci. Eng. A 494 (2008) 397-400.

[23] M. Matsuzuki, S. Horibe, Mater. Sci. Eng. A 504 (2009) 169-174.

[24] S. Begum, D.L. Chen, S. Xu, A.A. Luo, Mater. Sci. Eng. A 517 (2009) 334-343.

[25] M. Huppmann, M. Lentz, K. Brömmelhoff, W. Reimers, Mater. Sci. Eng. A 527 (2010) 5514-5521.

[26] C. Chen, T. Liu, Ch. Lv, L. Lu, D. Luo, Mater. Sci. Eng. A 539 (2012) 223-229.

[27] S.M. Yin, H.J. Yang, S.X. Li, S.D. Wu, F. Yang, Scr. Mater. 58 (2008) 751-754.

[28] Y.J. Wu, R. Zhu, J.T. Wang, Wen Qing Ji, Scr. Mater. 63 (2010) 1077-1080.

[29] F. Lv, F. Yang, S.X. Li, Z.F. Zhang, Scr. Mater. 65 (2011) 53-56.

[30] J. Ozaki, M. Yosida, S. Horibe, Mater. Sci. Eng. A 604 (2014) 192-195.

[31] S. Ishihara, S. Taneguchi, H. Shibata, T. Goshima, A. Saiki, Int. J. Fatigue 50 (2013) 94-100.

[32] J. Albinmousa, H. Jahed, S. Lambert, Int. J. Fatigue 33 (2011) 1127-1139.

[33] J. Albinmousa, H. Jahed, S. Lambert, Int. J. Fatigue 33 (2011) 1403-1416. 
[34] X. P. Zhang, S. Castagne, C. F. Gu, X. F. Luo, J. Mater. Sci. 46 (2011) 1124-1131.

[35] X.Z. Lin, D.L. Chen, Mater. Sci. Eng. A 496 (2008) 106-113.

[36] X.P. Zhang, S. Castagne, X.F. Luo, C.F. Gu, Mater. Sci. Eng. A 528 (2011) 838-845.

[37] Y. Xiong, Q. Yu, Y. Jiang, Mater. Sci. Eng. A 546 (2012) 119-128.

[38] W. Wu, S.Y. Lee, A.M. Paradowska, Y. Gao, P.K. Liaw, Mater. Sci. Eng. A 556 (2012) 278-286.

[39] G.S. Duan, B.L. Wu, X.H. Du, X. Zhao, Y.D. Zhang, L. Zuo, C. Esling, Mater. Sci. Eng. A 603 (2014) 11-22.

[40] S. Zheng, Q. Yu, Z. Gao, Y. Jiang, Eng. Fract. Mech. 114 (2013) 42-54.

[41] S. Zheng, Q. Yu, Y. Jiang, Int. J. Fatigue 47 (2013) 174-183.

[42] C.J. Geng, B.L. Wu, X.H. Du, Y.D. Wang, Y.D. Zhang, F. Wagner, C. Esling, Mater. Sci. Eng. A 560 (2013) 618-626.

[43] Q. Yu, J. Zhang, Y. Jiang, Q. Li, Int. J. Fatigue 33 (2011) 437-447.

[44] J. Zhang, Q. Yu, Y. Jiang, Q. Li, Int. J. Plasticity 27 (2011) 768-787.

[45] S. Kleiner, P.J. Uggowitzer, Mater. Sci. Eng. A 379 (2004) 258-263.

[46] J.B. Jordon, J.B. Gibson, M.F. Horstemeyer, H. El Kadiri, J.C. Baird, A.A. Luo, Mater. Sci. Eng. A 528 (2011) 6860-6871.

[47] Q. Li, Q. Yu, J. Zhang, Y. Jiang, Scr. Mater. 62 (2010) 778-781.

[48] Z.B. Sajuri, Y. Miyashita, Y. Mutoh., Fatigue Fract. Eng. Mater. Struct. 28 (2005) 373-379.

[49] M.S. Bhuiyan, Y. Mutoh, T. Murai, S. Iwakami, Int. J. Fatigue 30 (2008) 1756-1765.

[50] R.C. Zeng, W.Ke, E.H. Han, Int. J. Fatigue 31 (2009) 463-467.

[51] Q. Yu, J. Zhang, Y. Jiang, Q. Li, Int. J. Fatigue 36 (2012) 47-58.

[52] L. Wu, A. Jain, D.W. Brown, G.M. Stoica, S.R. Agnew, B. Clausen, D.E. Fielden, P.K. Liaw, Acta Mater. 56 (2008) 688-695.

[53] L. Wu, S.R. Agnew, D.W. Brown, G.M. Stoica, B. Clausen, A. Jain, D.E. Fielden, P.K. Liaw, Acta Mater. 56 (2008) 3699-3707.

[54] Y. Xiong, Q. Yu, Y. Jiang, Int. J. Plasticity 53 (2014) 107-124.

[55] Y. Xiong, Y. Jiang, Int. J. Fatigue 64 (2014) 74-83.

[56] S.H. Park, S.-G. Hong, B.H. Lee, W. Bang, C.S. Lee, Int. J. Fatigue 32 (2010) 1835-1842.

[57] F. Lv, F. Yang, Q.Q. Duan, Y.S. Yang, S.D. Wu, S.X. Li, Z.F. Zhang, Int. J. Fatigue 33 (2011) 672-682.

[58] S.-G. Hong, S.H. Park, Y.-H. Huh, C.S. Lee, J. Mater. Res. 25 (2010) 966-971.

[59] S.H. Park, S.-G. Hong, W. Bang, C.S. Lee, Mater. Sci. Eng. A 527 (2010) 417-423.

[60] F. Lv, F. Yang, Q.Q. Duan, T.J. Luo, Y.S. Yang, S.X. Li, Z.F. Zhang Scr. Mater. 61 (2009) 887-890.

[61] S.H. Park, S.-G. Hong, C.S. Lee, Scr. Mater. 62 (2010) 666-669. 
[62] A.N. Chamos, Sp.G. Pantelakis, G.N. Haidemenopoulos, E. Kamoutsi, Fatigue Fract. Eng. Mater. Struct. (2008) 812-821.

[63] G. Huang, J. Li, T. Han, H. Zhang, F. Pan, Materials and Design 58 (2014) 439-444.

[64] L. Wu, S.R. Agnew, Y.Ren, D.W. Brown, B. Clausen, G.M. Stoica, H.R. Wenk, P.K. Liaw, Mater. Sci. Eng. A 527 (2010) 7057-7067.

[65] T. Hama, Y. Kariyazaki, N. Hosokawa, H. Fujimoto, H. Takuda, Mater. Sci. Eng. A 551 (2012) 209-217.

[66] Y.C. Lin, X.-M. Chen, G. Chen, J. Alloys Compd. 509 (2011) 6838-6843.

[67] Y.C. Lin, X.-M. Chen, Z.H. Liu, J. Chen, Int. J. Fatigue 48 (2013) 122-132.

[68] X.-M. Chen, Y.C. Lin, J. Chen, J. Alloys Compd. 579 (2013) 540-548.

[69] T.J. Luo, Y.S. Yang, W.H. Tong, Q.Q. Duan, X.G. Dong, Materials and Design 31 (2010) 1617-1621.

[70] S. Begum, D.L. Chen, S. Xu, A.A. Luo, Metall. Mater. Trans. A 39 (2008) 3014-3026.

[71] C.L. Fan, D.L. Chen, A.A. Luo, Mater. Sci. Eng. A 519 (2009) 38-45.

[72] J.B. Jordon, H.R. Brown, H.E. Kadiri, H.M. Kistler, R.L. Lett, J.C. Baird, A.A. Luo, Int. J. Fatigue 51 (2013) 8-14.

[73] L. Chen, C. Wang, W. Wu, Z. Liu, G.M. Stoica, L. Wu, P.K. Liaw, Metall. Mater. Trans. A 38 (2007) 2235-2241.

[74] F. Akbaripanah, F. Fereshteh-Saniee, R. Mahmudi, H.K. Kim, Mater. Sci. Eng. A 565 (2013) 308-316.

[75] W. Liu, J. Dong, P. Zhang, C. Zhai, W. Ding, Mater. Trans. 50 (2009) 791-798.

[76] J. Müller, M. Janecek, S. Yi, J. Cizek, L. Wagner, Int. J. Mater. Res. 100 (2009) 838-842.

[77] F. Novy, M. Janecek, V. Skorik, J. Müller, L. Wagner, Int. J. Mater. Res. 100 (2009) 288-291.

[78] D. Xu, L. Liu, Y. Xu, E. Han, Acta Metall Sin. 43 (2007) 144-148.

[79] J. Bohlen, S.B. Yi, J. Swiostek, D. Letzig, H.G. Brokmeier, K.U. Kainer, Scr. Mater. 53 (2005) 259-264.

[80] S.-B. Yi, H.-G. Brokmeier, D. Letzig, J. Alloys Compd. 506 (2010) 364-371.

[81] J. Koike, Metall. Mater. Trans. A 36 (2005) 1689-1696.

[82] O. Muránsky, D.G. Carr, P. Šittner, E.C. Oliver, Int. J. Plasticity 25 (2009) 1107-1127.

[83] S.R. Agnew, D.W. Brown, C.N. Tomé, Acta Mater. 54 (2006) 4841-4852.

[84] M.D. Nave, M.R. Barnett, Scr. Mater. 51 (2004) 881-885.

[85] O. Muránsky, D.G. Carr, M.R. Barnett, E.C. Oliver, P. Sittner, Mater. Sci. Eng. A 496 (2008) 14-24.

[86] S.-B. Yi, C.H.J. Davies, H.-G. Brokmeier, R.E. Bolmaro, K.U. Kainer, J. Homeyer, Acta Mater. 54 (2006) 549-562. 
[87] P. Cizek, M.R. Barnett, Scr. Mater. 59 (2008) 959-962.

[88] M.R. Barnett, Z. Keshavarz, A.G. Beer, X. Ma, Acta Mater. 56 (2008) 5-15.

[89] D. Ando, J. Koike, Y. Sutou, Acta Mater. 58 (2010) 4316-4324.

[90] Q. Ma, H. El Kadiri, A.L. Oppedal, J.C. Baird, M.F. Horstemeyer, M. Cherkaoui, Scr. Mater. 64 (2011) 813-816.

[91] A.G. Croker, Philos. Mag. 7 (1962) 1901.

[92] E. Ma, Y.M. Wang, Q.H. Lu, M.L. Sui, L. Lu, K. Lu, Appl. Phys. Lett. 85 (2004) 4932-4934.

[93] K. Máthis, Z. Trojanová, P. Lukác, C.H. Cáceres, J. Lendvai, J. Alloys Compd. 378 (2004) $176-179$.

[94] I.A. Yakubtsov, B.J. Diaka, C.A. Sager, B. Bhattacharya, W.D. MacDonald, M. Niewczas, Mater. Sci. Eng. A 496 (2008) 247-255.

[95] F. Wang, J. Dong, Y. Jiang, W. Ding, Mater. Sci. Eng. A 561 (2013) 403-410.

[96] C. Sommer, H.-J. Christ, H. Mughrabi, Acta Metall. Mater. 39 (1991) 1177-1187.

[97] Y. Jiang, ASME J. Eng. Mat. Tech. 123(2001) 274-280.

[98] J. Zhang, Y. Jiang, Int. J. Plasticity 21(2005) 2174-2190. 